\title{
Phosphodiesterase 2A as a therapeutic target to restore cardiac neurotransmission during sympathetic hyperactivity
}

Kun Liu, ${ }^{1}$ Dan Li, ${ }^{1}$ Guoliang Hao, ${ }^{1}$ David McCaffary, ${ }^{1}$ Oliver Neely, ${ }^{1}$ Lavinia Woodward, ${ }^{1}$

Demetris loannides, ${ }^{1}$ Chieh-Ju Lu, ${ }^{1}$ Marcella Brescia, ${ }^{1}$ Manuela Zaccolo, ${ }^{1}$ Harikrishna Tandri, ${ }^{2}$ Olujimi A. Ajijola, ${ }^{3}$ Jeffrey L. Ardell, ${ }^{3}$ Kalyanam Shivkumar, ${ }^{3}$ and David J. Paterson ${ }^{1}$

'Burdon Sanderson Cardiac Science Centre and BHF Centre of Research Excellence, Department of Physiology, Anatomy and Genetics, University of Oxford, Oxford, United Kingdom. 'Division of Cardiology, Department of Medicine, Johns Hopkins University, Baltimore, Maryland, USA. ${ }^{3}$ UCLA Cardiac Arrhythmia Center, David Geffen School of Medicine, UCLA Health System, Los Angeles, California, USA.

Elevated levels of brain natriuretic peptide (BNP) are regarded as an early compensatory response to cardiac myocyte hypertrophy, although exogenously administered BNP shows poor clinical efficacy in heart failure and hypertension. We tested whether phosphodiesterase 2A (PDE2A), which regulates the action of BNP-activated cyclic guanosine monophosphate (cGMP), was directly involved in modulating $\mathrm{Ca}^{2+}$ handling from stellate ganglia (SC) neurons and cardiac norepinephrine (NE) release in rats and humans with an enhanced sympathetic phenotype. SG were also isolated from patients with sympathetic hyperactivity and healthy donor patients. PDE2A activity of the SC was greater in both spontaneously hypertensive rats (SHRs) and patients compared with their respective controls, whereas PDE2A mRNA was only high in SHR SC. BNP significantly reduced the magnitude of the calcium transients and $I_{\mathrm{CaN}}$ in normal Wistar Kyoto (WKY) SC neurons, but not in the SHRs. cGMP levels stimulated by BNP were also attenuated in SHR SC neurons. Overexpression of PDE2A in WKY neurons recapitulated the calcium phenotype seen in SHR neurons. Functionally, BNP significantly reduced $\left[{ }^{3} \mathrm{H}\right]-\mathrm{NE}$ release in the WKY rats, but not in the SHRs. Blockade of overexpressed PDE2A with Bay 60-7550 or overexpression of catalytically inactive PDE2A reestablished the modulatory action of BNP in SHR SC neurons. This suggests that PDE2A may be a key target in modulating the action of BNP to reduce sympathetic hyperactivity.

Authorship note: $\mathrm{KL}$, DL, and GH contributed equally to this work.

Conflict of interest: The authors have declared that no conflict of interest exists.

Submitted: November 17, 2017

Accepted: April 5, 2018

Published: May 3, 2018

Reference information: JCI Insight. 2018;3(9):e98694. https://doi.org/10.1172/jci. insight. 98694.

\section{Introduction}

Elevated levels of brain natriuretic peptide (BNP) may provide compensation in pathologies associated with heart failure, hypertension, and cardiac dysautonomia (1). Cyclic nucleotide phosphodiesterases (PDEs) are enzymes that regulate the cellular levels of cyclic adenosine monophosphate (cAMP) and cyclic guanosine monophosphate (cGMP) by controlling their rates of degradation in response to different stimuli such as natriuretic peptides (2) and $\beta$-adrenergic receptors (3). Among the PDE superfamily, PDE2A as a dual-specificity enzyme has received considerable attention because it is markedly upregulated in heart failure and blunts $\beta$-adrenergic responses via hydrolysis of cAMP in cardiomyocytes $(4,5)$. It also affects the action of BNP to stimulate CGMP, reducing protein kinase G (PKG) inhibition of intracellular calcium concentration $\left(\left[\mathrm{Ca}^{2+}\right]_{\mathrm{i}}\right)$ and subsequent neurotransmitter release (6). This indicates that manipulation of PDE2A might either be beneficial or deleterious depending on the target cell.

Physiologically, raised BNP is well established to bring about beneficial effects on cardio-renal homeostasis (7) and sympatho-vagal balance (8); therefore, infused BNP should theoretically have positive clinical utility in a number of cardiovascular pathologies. However, large-scale, randomized, double-blinded, and placebo-controlled trials such as FUSION II (9) and ASCEND-HF (10) failed to demonstrate efficacy using a recombinant form of human BNP, nesiritide, in the setting of acute decompensated heart failure. These disappointing results were compounded by the meta-analysis (11), suggesting that nesiritide may 
actually increase mortality (12) where BNP might facilitate norepinephrine (NE) release (in PC12 cells) and provide a trigger for arrhythmia (13). Interestingly, the sympatholytic action of paracrine BNP is substantially attenuated when PDE2A activity is enhanced in cardiac stellate neurons (6), which is observed during dysautonomia associated with hypertension (14) and heart failure (4).

Therefore, we tested if PDE2A is present in human stellate ganglia (SG) and hypothesized that its levels are enhanced in neurons from patients with sympathetic overdrive. These SG were derived from patients undergoing stellectomy for treatment of intractable ventricular arrhythmias (15) and were compared to those harvested from organ donors. We also tested in a rat model of sympathetic hyperactivity whether BNP loses its efficacy on postganglionic stellate sympathetic neurons due to over-activity of PDE2A, thereby impairing CGMP-PKG via regulation of the neuronal calcium current, intracellular calcium transient, and with resultant effects on cardiac NE release. We identified PDE2A in human and rat SG and found increased PDE2A activity in SG from patients with refractory ventricular arrhythmias and rats that exhibit a sympathetic phenotype. Moreover, we demonstrate that blockade of overexpressed PDE2A or overexpression of catalytically inactive PDE2A in SG neurons reverse-remodeled the modulatory actions of BNP to decrease $\mathrm{Ca}^{2+}$-induced exocytosis and neurotransmission.

\section{Results}

Impaired cGMP signaling in SHR neurons following BNP stimulation. Real-time measurements of intracellular cGMP concentration in living cardiac sympathetic neurons were performed using ratiometric fluorescence resonance energy transfer (FRET) imaging in the presence of exogenous BNP (10, 100, $250 \mathrm{nmol} / \mathrm{l}$; Figure 1A). BNP increased cGMP levels in a dose-dependent manner (calculated as a mean of the 4 values prior to the addition of the subsequent dose). However, the cGMP response to BNP was attenuated in spontaneously hypertensive rat (SHR) neurons relative to Wistar neurons at 100 and $250 \mathrm{nmol} / 1(10 \mathrm{nmol} / 1$ : Wistar $=1.60 \pm 0.31 \%$, SHR $=1.10 \pm 0.30 \%, P=0.262 ; 100 \mathrm{nmol} / 1:$ Wistar $=4.02 \pm 0.73 \%, \mathrm{SHR}=2.16 \pm 0.46 \%, P=0.043 ; 250 \mathrm{nmol} / 1$ : Wistar $=6.16 \pm 0.70 \%$, SHR $=3.89 \pm 0.61 \%, P=0.021$; Wistar $n=14$, SHR $n=15$; Figure 1B). In order to investigate the contribution of PDE2A and total PDE to the different cGMP responses between SHRs and Wistar rats, the specific PDE2A inhibitor Bay 60-7550 (1 $\mu \mathrm{mol} / \mathrm{l})$ and nonspecific PDE inhibitor 3-isobutyl1-methylxanthine (IBMX; $100 \mu \mathrm{mol} / \mathrm{l}$ ) were added in the presence of $100 \mathrm{nmol} / 1 \mathrm{BNP}$. Both Bay $60-7550$ and IBMX abolished the differences in the cGMP generation stimulated by $100 \mathrm{nmol} / 1 \mathrm{BNP}$ (Figure 1B). There was also no difference between the Bay 60-7550 and IBMX responses, suggesting that PDE2A is the major PDE linked to the reduction of cGMP in the SHR sympathetic neurons.

Enhanced PDE2A expression and activity in SG from disease models. Here we show the presence of PDE2A in human SG. cGMP-PDE2A specific activity in patients was higher $(134.6 \pm 10.1 \mathrm{pmol} / \mathrm{mg} / \mathrm{min}$, from 5 left SG) compared with donors $(75.6 \pm 17.1 \mathrm{pmol} / \mathrm{mg} / \mathrm{min}$, from 4 left SG $P=0.028$; Figure $2 \mathrm{~A})$. Total PDE activity was not statistically different, although there was a trend for an increase in the diseased group (Figure 2A). There was also no significant difference in right SG between patients and the control group (Figure 2A). cGMP-PDE2A specific activity was enhanced in 38-week-old SHRs $(96.8 \pm 6.8 \mathrm{pmol} / \mathrm{mg} /$ $\min , n=6$ pairs of SG) compared with the age-matched Wistar Kyoto (WKY) rats $(52.8 \pm 3.0 \mathrm{pmol} / \mathrm{mg} /$ $\min , n=6$ pairs SG) $(P=0.04$; Figure $2 \mathrm{~B})$. This is similar to that previously reported for PDE2A activity in 4-week-old SHRs (6). Total PDE activity and that following PDE2A inhibition (1 $\mu$ mol/1 Bay 60-7550) were not statistically different $(P=0.053$ and 0.066 , respectively; Figure $2 \mathrm{~B})$; there was a trend for an increase in the diseased group, suggesting that other PDEs might also be enhanced in 38-week-old SHRs. For the cAMP-PDE specific activity, no difference was detected in total PDE, with PDE2A inhibition (1 $\mu \mathrm{mol} / 1$ Bay 60-7550) and relative PDE2A activity (Figure 2C) between 4-week-old SHR and WKY SG.

Quantitative real-time PCR (qRT-PCR) analysis of relative PDE2A mRNA levels showed the presence of PDE2A gene expression in patients and donors ( $n=4$ left and right SG in each group), although there was no difference due to lack of statistical power (Figure 2D) and probably reflects clinical heterogeneity in the human samples (see Table 1). PDE2A mRNA levels in 4-week-old WKY rats were significantly lower than age-matched SHRs ( $n=6$ in each group, $P=0.04$; Figure $2 \mathrm{E}$ ), suggesting some conservation of this molecular phenotype across species and developmental state.

Effect of BNP on NE release from WKY rats and SHRs. To test whether neurotransmitter release is altered in prehypertensive rats, we directly measured the level of $\left[{ }^{3} \mathrm{H}\right]-\mathrm{NE}$ release in response to field stimulation of the right atrium. There was no difference between the peak of the first (S1) and second (S2) field stimulation (5 Hz for 1 minute) in both the WKY (S1: $+0.72 \% \pm 0.09 \%, \mathrm{~S} 2:+0.69 \% \pm 0.04 \%, n=6, t$ test, $P=$ 


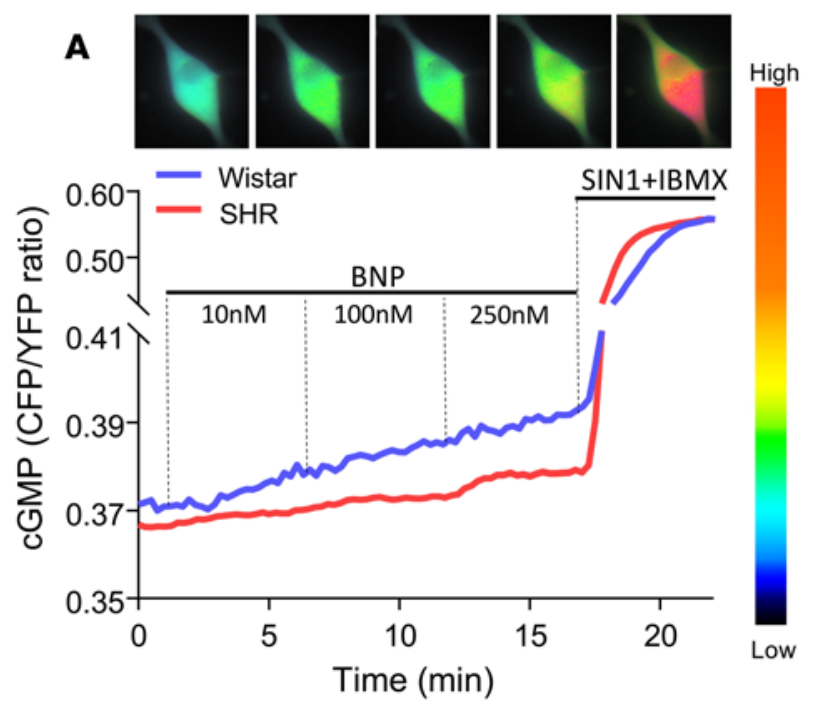

B
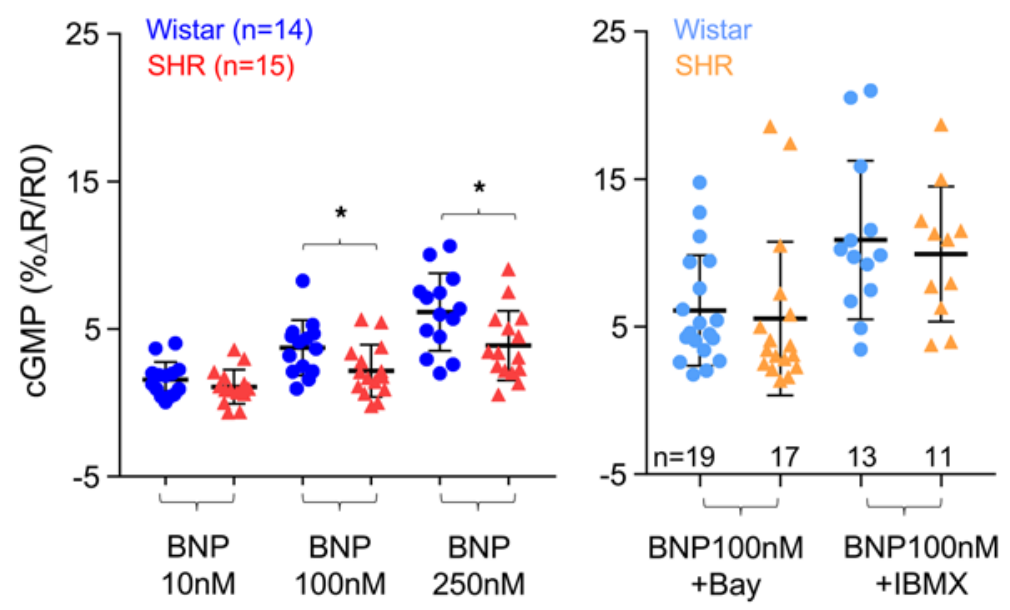

Figure 1. Measurements of intracellular CGMP concentration in living cardiac sympathetic neurons in the presence of BNP. (A) Representative data traces showing dynamics of cytosolic cGMP-induced fluorescence resonance energy transfer (FRET) changes by ratiometric recording of CFP and YFP emission changes in response to increasing concentrations of brain natriuretic peptide (BNP) in spontaneously hypertensive rat (SHR) and Wistar cardiac sympathetic neurons. Saturation of the sensor was achieved using 3-morpholinosydnonimine chloride (SIN-1 chloride; $10 \mu \mathrm{mol} / \mathrm{l}$; Calbiochem, 16142-27-1) + IBMX (100 $\mu \mathrm{mol} / \mathrm{I})$. (B) Percentage changes in CGMP in response to increasing concentrations of BNP (left, from 10-250 $\mathrm{nmol} / \mathrm{l}$ ) and $100 \mathrm{nmol} / \mathrm{l}$ BNP with $1 \mu \mathrm{mol} / \mathrm{l}$ Bay $60-7550$ or $100 \mu \mathrm{mol} / \mathrm{l}$ IBMX (right) in SHRs and Wistar rats. ${ }^{*} P<0.05$ by unpaired $t$ test. In each case, neurons were derived from 3 or more rats. $n$ indicates number of SG neurons.

$0.724)$ and SHR group (S1: $+1.01 \% \pm 0.12 \%, \mathrm{~S} 2:+1.03 \% \pm 0.15 \%, n=7, t$ test, $P=0.946$; Figure $3, \mathrm{~A}$ and $B)$, indicating no significant time-dependent changes. However, the level of $\left[{ }^{3} \mathrm{H}\right]-\mathrm{NE}$ release in SHRs was significantly higher than WKY rats at both baseline (WKY: $2.392 \% \pm 0.078 \%, n=6$ vs. SHR: $3.314 \% \pm$ $0.19 \%, n=7, P<0.01$ by unpaired $t$ test) and after 5 -Hz field stimulation (S1: WKY: $0.71 \% \pm 0.09 \%, n=6$ vs. SHR: $1.06 \% \pm 0.10 \%, n=7, P<0.05$; S2: WKY: $0.65 \% \pm 0.06 \%, n=6$ vs. SHR: $1.1 \% \pm 0.11 \%, n=7$, $P<0.05$ by 1 -way ANOVA; Figure $3, \mathrm{~A}$ and $\mathrm{B}$ ).

To investigate whether BNP affected $\left[{ }^{3} \mathrm{H}\right]-\mathrm{NE}$ release during $5-\mathrm{Hz}$ field stimulation, a high concentration $(250 \mathrm{nmol} / 1)$ of BNP was added 27 minutes after the first stimulation. This produced an approximately $38 \%$ reduction of $[3 \mathrm{H}]-\mathrm{NE}$ release in the WKY rats $(\mathrm{S} 1:+1.07 \% \pm 0.08 \%, \mathrm{~S} 2:+0.66 \% \pm 0.05 \%, n=9, P$ $=0.04$ by 1 -way ANOVA). However, BNP failed to change $\left[{ }^{3} \mathrm{H}\right]-\mathrm{NE}$ release in the SHRs $(\mathrm{S} 1:+1.17 \% \pm$ $0.15 \%, \mathrm{~S} 2:+1.18 \% \pm 0.14 \%, n=9, P=0.97$ by 1 -way ANOVA; Figure 3, C and D).

Effect of BNP on calcium current $\left(I_{\text {CaN }}\right)$ and intracellular free calcium transients in SG neurons in WKY rats and SHRs. We next investigated whether BNP would affect calcium signaling in isolated SG neurons from SHRs and WKY rats. Anti-tyrosine hydroxylase (TH, sympathetic neuron marker) and anti-PDE2A immunofluorescence staining from fixed cultured SG neurons is shown in Figure 4A, confirming that PDE2A was expressed in sympathetic neurons. The peak $I_{\mathrm{CaN}}$ was significantly reduced by $-18.2 \% \pm 7.2 \%(P<0.05, n$ = 6) after 10-minute exposure to $100 \mathrm{nmol} / 1 \mathrm{BNP}$ in WKY neurons (Figure 4B), but BNP failed to affect the SHR neurons (Figure 4B). However, BNP restored its inhibitory action following inhibition of PDE2A with Bay $60-7550(1 \mu \mathrm{mol} / 1$, reduced by $-12.5 \% \pm 6.3 \%, P<0.05, n=6$; Figure $4 \mathrm{~B})$. 


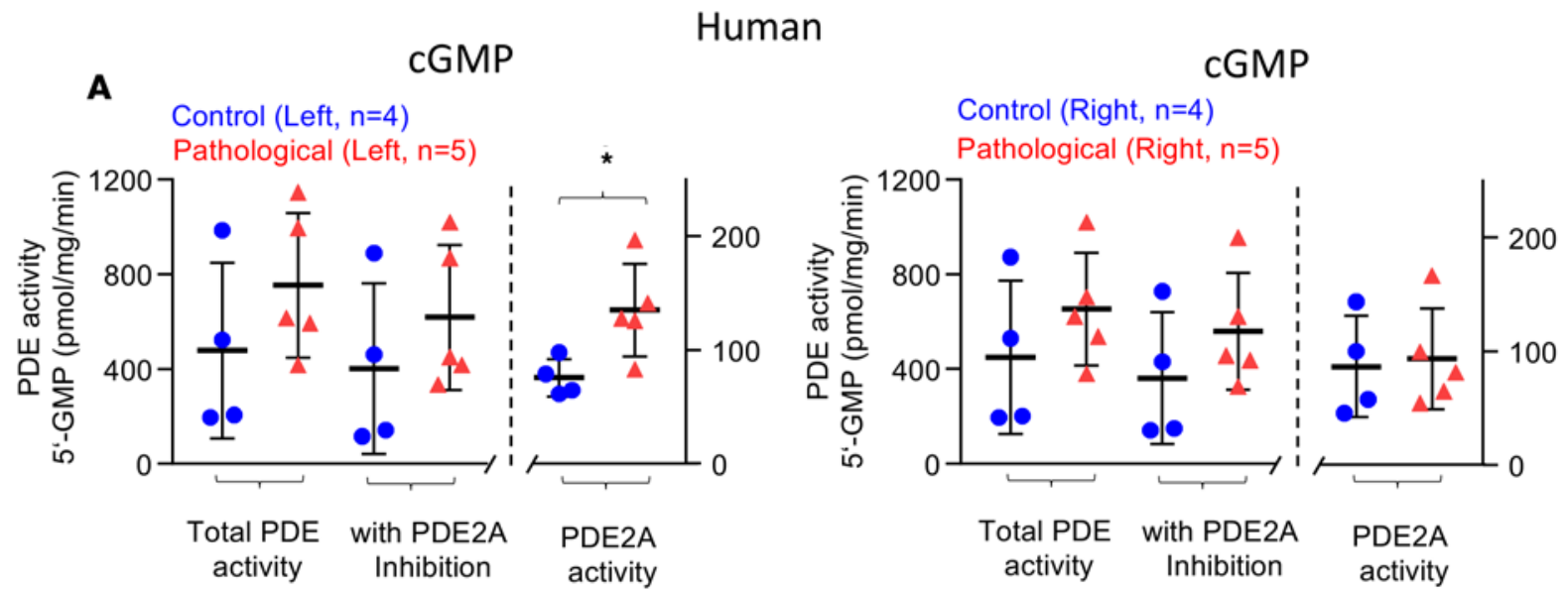

\section{B}

cGMP

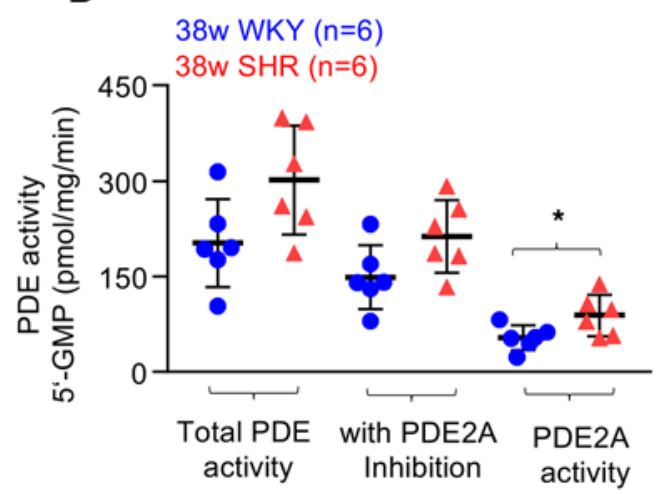

Rat

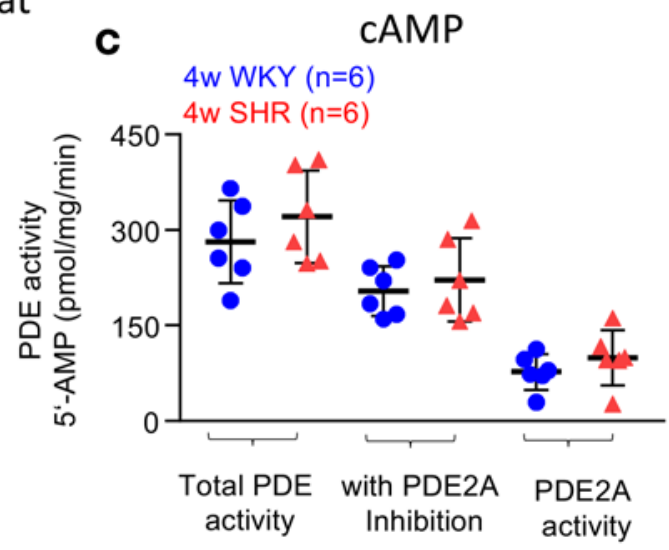

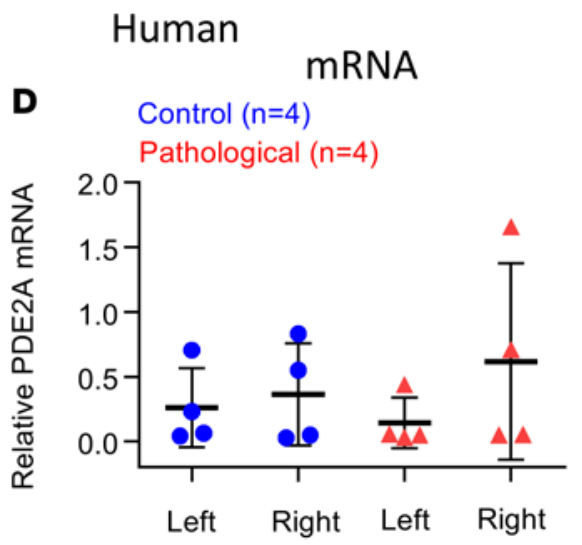

Rat

E

mRNA

4W WKY $(n=7)$

4 W SHR $(n=7)$

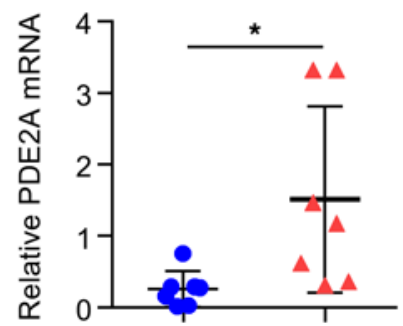

Figure 2. Measurement of PDE activity and relative PDE2A mRNA levels in stellate ganglia from human and rat. (A) Representative data showing CGMP-PDE specific activities and relative PDE2A activities in left and right stellate ganglia tissue from sympathetic hyperactive patients (pathological) and normal control; and (B) in stellate ganglia tissue from 38-week-old Wistar Kyoto (WKY) rats and spontaneously hypertensive rats (SHRs). (C) CAMP-PDE specific activities and relative PDE2A activities in stellate ganglia tissue from 4-week-old WKY rats and SHRs. Quantitative RT-PCR analysis of PDE2A mRNA levels in stellate ganglia tissue of sympathetic hyperactive patients (pathological) and normal control (D) and 4-week-old WKY rats and SHRs $(E)$; data are shown as mean \pm SEM. ${ }^{*} P<0.05$ by unpaired $t$ test. Left: left stellate ganglion; Right: right stellate ganglion in human. $n$ indicates stellate ganglia number. 
Table 1. Clinical characteristics of human tissue samples

\begin{tabular}{|c|c|c|c|c|c|}
\hline Sample ID & Group & Age & Sex & LVEF & Clinical characteristics \\
\hline 2 & Control $(L+R)$ & 52 & Male & $70 \%$ & CVA with hemorrhage (normal heart) \\
\hline 5 & Control $(\mathrm{L}+\mathrm{R})$ & 45 & Female & $70 \%-75 \%$ & $\begin{array}{c}\text { Right MCA aneurysm rupture, subarachnoid hemorrhage with } \\
\text { herniation (normal heart) }\end{array}$ \\
\hline 6 & Control (L) & 30 & Female & $55 \%-60 \%$ & $\begin{array}{l}\text { Cardiac arrest - smoker, lung donor, toxic positive for } \\
\text { methamphetamine, marijuana (normal heart) }\end{array}$ \\
\hline 7 & Control (L+R) & 37 & Male & $57 \%$ & ICH (normal heart) \\
\hline 9 & Pathology $(L+R)$ & 46 & Male & $30 \%$ & NICM, VC \\
\hline 10 & Pathology $(L+R)$ & 30 & Male & $15 \%$ & NICM \\
\hline 11 & Pathology $(L+R)$ & 45 & Female & $38 \%$ & Sarcoid cardiomyopathy \\
\hline 14 & Pathology $(L+R)$ & 65 & Male & $35 \%$ & NICM \\
\hline 15 & Pathology $(L+R)$ & 69 & Male & $20 \%$ & NICM, CAD (mild, nonobstructive) \\
\hline 16 & Control (L+R) & 56 & Male & $>60 \%$ & Normal heart \\
\hline 17 & Control (L+R) & 49 & Male & $>60 \%$ & Normal heart \\
\hline 19 & Pathology $(L+R)$ & 77 & Male & $30 \%-35 \%$ & NICM, VF \\
\hline 20 & Control (L+R) & 61 & Female & $\begin{array}{l}\text { Presumably } \\
\text { normal }\end{array}$ & $\begin{array}{l}\text { Aortic and carotid dissection } \rightarrow \text { anoxic brain injury. Hypertension, } \\
\text { hypothyroidism. No known CAD. Tobacco use for 30-40 yr }\end{array}$ \\
\hline 21 & Pathology $(L+R)$ & 34 & Female & Not available & Excessive tachycardia, normal heart \\
\hline 22 & Pathology $(L+R)$ & 70 & Male & $30 \%$ & ICM, VT, low EF \\
\hline 23 & Control $(\mathrm{L}+\mathrm{R})$ & 19 & Male & $55 \%-60 \%$ & $\begin{array}{c}\text { Normal heart size, and chambers, no lung problems some atelectasis } \\
\text { that improved }\end{array}$ \\
\hline 24 & Pathology $(L+R)$ & 62 & Male & $50 \%$ & NICM, LVEF 30\%, improved to 50\%, PMVT/VF with high PVC burden \\
\hline \multicolumn{6}{|c|}{$\begin{array}{l}\text { LVEF, left ventricular ejection fraction; L, left stellate ganglion; R, right stellate ganglion; CVA, cerebrovascular accident; MCA, middle cerebral } \\
\text { artery; ICH, intracranial hemorrhage; NICM, nonischemic cardiomyopathy; VC, valvular cardiomyopathy; CAD, coronary artery disease; VF, ventricular } \\
\text { fibrillation; ICM, implantable cardiac monitor; VT, ventricular tachycardia; EF, ejection fraction; PMVT, polymorphic ventricular tachycardia; PVC, } \\
\text { premature ventricular contraction. }\end{array}$} \\
\hline
\end{tabular}

We measured intracellular calcium concentration using ratiometric recordings (with fura-2-acetoxymethyl ester, Fura-2/AM) in single SG neurons. A protocol for the calcium-transient response to $50 \mathrm{mmol} / 1$ $\mathrm{KCl}$ is shown in Figure 4C. BNP was introduced 7 minutes after the first $\mathrm{KCl}$ application. After 10 minutes of treatment, neurons were stimulated again (S2) in the presence of different concentrations of BNP with or without the PDE2A inhibitor Bay 60-7550. In the WKY rats, 100 or $250 \mathrm{nmol} / 1 \mathrm{BNP}$ caused a reduction in $\left[\mathrm{Ca}^{2+}\right]_{i}$ evoked by high $\mathrm{K}^{+}$depolarization by approximately $22 \%(n=13)$ and $20 \%(n=13)$, respectively. In the presence of Bay 60-7550 (1 $\mu \mathrm{mol} / 1)$, application of BNP reduced the $\left[\mathrm{Ca}^{2+}\right]_{\mathrm{i}}$ transient by $-23.32 \% \pm$ $5.1 \%(n=10, P<0.01)$ at $100 \mathrm{nmol} / 1$, and $-21.17 \% \pm 3.4 \%(n=10, P<0.01)$ at $250 \mathrm{nmol} / 1$ (Figure 4D) in the WKY rats. In contrast, BNP alone did not affect evoked $\left[\mathrm{Ca}^{2+}\right]_{\mathrm{i}}$ in the SHRs $(90.51 \% \pm 2.71 \%$ at 100 $\mathrm{nmol} / \mathrm{l}, n=10$, and $108.91 \% \pm 4.22 \%$ at $250 \mathrm{nmol} / 1, n=12$; Figure $4 \mathrm{D})$. Moreover, the inhibitory action of BNP was unmasked by the presence of PDE2A inhibitor (100 nmol/1 BNP: $-24.3 \% \pm 3.1 \%, n=11, P<$ $0.001 ; 250 \mathrm{nmol} / 1 \mathrm{BNP}:-13.6 \% \pm 3.6 \%, n=11, P<0.05$; Figure $4 \mathrm{D})$. Taken together, these results suggest there is significant cellular impairment in SG neurons from prehypertensive rats involving the BNP-cGMPPDE2A pathway linked to calcium signaling.

Overexpression of $P D E 2 A$ in stellate neurons from normotensive rats prevents the inhibitory action of $B N P$. To directly test the hypothesis that increased PDE2A activity abolishes the capacity of BNP to reduce $\left[\mathrm{Ca}^{2+}\right]_{i}$ in depolarized neurons, Ad.CMV-mCherry/PDE2A or its control vector (Ad.CMV-mCherry) was transduced in the neurons of the WKY rat. Western blot showed that PDE2A.mCherry expression (135 kDa, with anti-PDE2A antibody) was significantly enhanced in Ad.PDE2A transduced SG tissue when compared with those transduced with the mCherry virus alone ( $n=4$ in each group; Figure $5 \mathrm{~A})$.

We then compared $I_{\mathrm{CaN}}$ in WKY SG neurons transduced with the mCherry virus and Ad.PDE2A virus. BNP $(100 \mathrm{nmol} / 1)$ reduced $I_{\mathrm{CaN}}(-21.7 \% \pm 6.1 \%, n=9, P<0.05$; Figure $5 \mathrm{~B})$ in neurons transduced with the mCherry virus. However, $100 \mathrm{nmol} / 1 \mathrm{BNP}$ failed to reduce $I_{\mathrm{CaN}}(n=7, P=0.79$; Figure $5 \mathrm{~B})$ in the WKY SG neurons overexpressing PDE2A. Interestingly, $100 \mathrm{nmol} / 1 \mathrm{BNP}$ in the presence of Bay 60-7550 decreased the calcium current $(-14.4 \% \pm 5.7 \%, n=6, P<0.05$; Figure $5 \mathrm{~B})$ in these neurons overexpressing PDE2A, thus restoring the efficacy of BNP. 

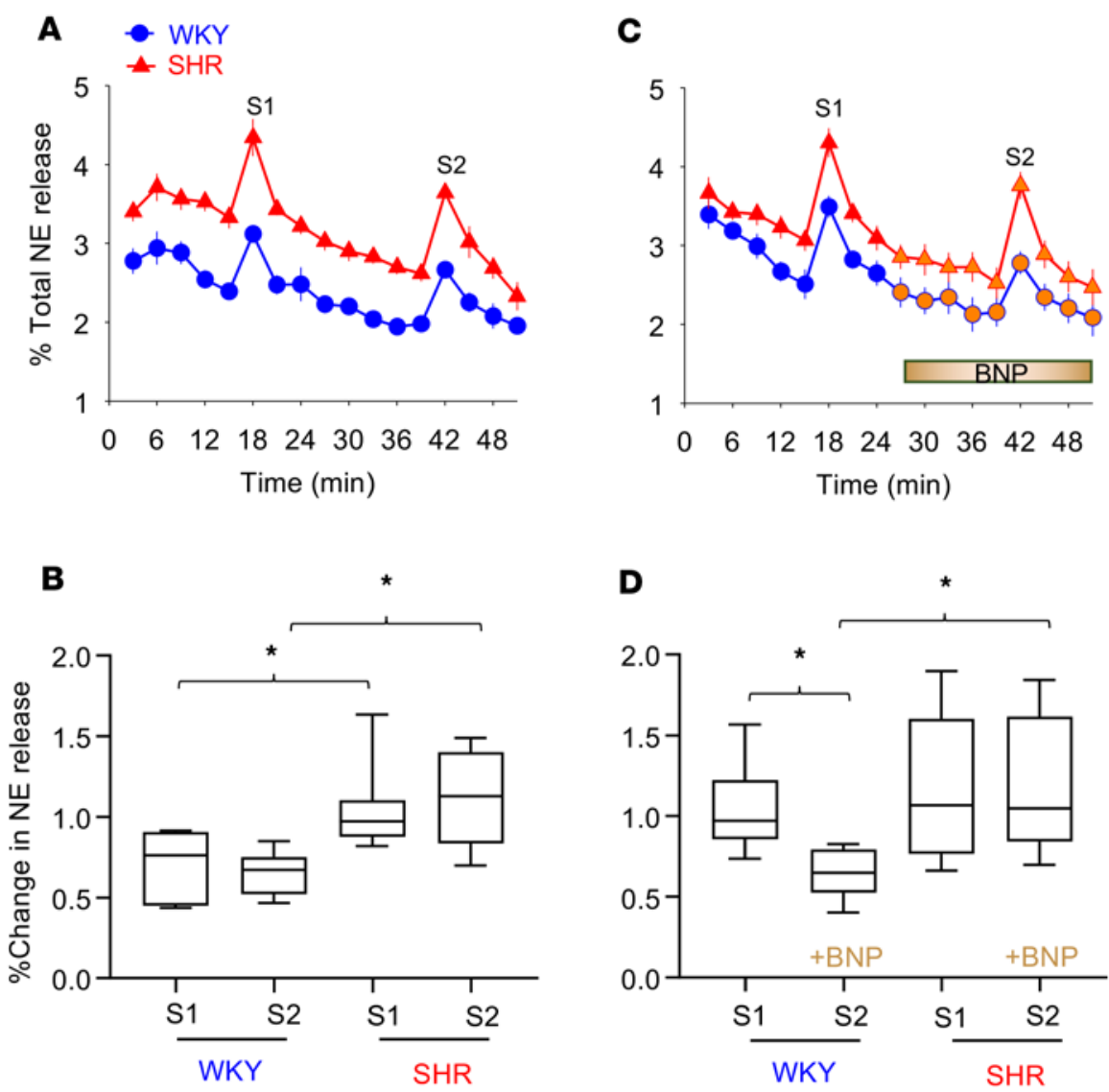

Figure 3. Effect of BNP on the norepinephrine release from isolated atria. (A) Representative group raw data traces showing the time control for $\left[{ }^{3} \mathrm{H}\right]$-norepinephrine $\left(\left[{ }^{3} \mathrm{H}\right]-\mathrm{NE}\right)$ release from isolated atria harvested from 4-week-old Wistar Kyoto (WKY) rats and spontaneously hypertensive rats (SHRs). The atria were stimulated at $5 \mathrm{~Hz}$ for 1 minute at the 16th (S1) and 40th (S2) minutes. (B) Group mean data show no significant changes between S1 and S2 within group in response of $5 \mathrm{~Hz}$ stimulation evoked $\left[{ }^{3} \mathrm{H}\right]-\mathrm{NE}$ release of time control. However, both $\mathrm{S} 1$ and $\mathrm{S} 2$ are significantly enhanced in the SHRs compared with the WKY rats (WKY: $n=6$, SHR: $n=7$ ). ${ }^{*} P<0.05$ by 1-way ANOVA. (C) Same as in A but with the addition of $250 \mathrm{nmol} / \mathrm{l}$ brain natriuretic peptide (BNP). Group raw data traces (C) and mean data (D) show that BNP caused a significant decrease in $5-\mathrm{Hz}$ stimulation-evoked $\left[{ }^{3} \mathrm{H}\right]-\mathrm{NE}$ release (S2) in WKY rats, but not in SHRs (WKY: $n=10$, SHR: $n=9) .{ }^{*} P<0.05$ by 1-way ANOVA. Percentage changes in NE release was expressed as a ratio of increase in $\mathrm{NE}$ radioactivity after electrical stimulation over the total radioactivity.

For the intracellular calcium transient, after transduction with Ad.PDE2A, $100 \mathrm{nmol} / 1 \mathrm{BNP}$ failed to reduce the depolarization-induced $\left[\mathrm{Ca}^{2+}\right]_{\mathrm{i}}$ transient $(-6.7 \% \pm 4.0 \%, n=7, P=0.79$; Figure $5 \mathrm{C})$. Indeed, there was a trend for $250 \mathrm{nmol} / 1 \mathrm{BNP}$ to increase $\left[\mathrm{Ca}^{2+}\right]_{\mathrm{i}}(+7.8 \% \pm 13.9 \%, n=8, P=0.99 ;$ Figure $5 \mathrm{C})$ when compared with the control group. In contrast, BNP (100 and $250 \mathrm{nmol} / 1)$ reduced $\left[\mathrm{Ca}^{2+}\right]_{\mathrm{i}}$ in WKY neurons transduced with the mCherry virus (Figure 5C). Moreover, 100 or $250 \mathrm{nmol} / 1 \mathrm{BNP}$ in the presence of Bay 60-7550 (1 $\mu \mathrm{mol} / \mathrm{l})$ caused a decrease in peak $\left[\mathrm{Ca}^{2+}\right]_{\mathrm{i}}(-27.3 \% \pm 2.5 \%, n=11, P<0.05$ or $-32 \% \pm 4.1 \%, n=9, P<0.05$; Figure 5C) in the WKY neurons overexpressing PDE2A. Thus, as in SHR neurons, concurrent PDE2A inhibition restores the capacity of BNP to decrease calcium transients. Collectively, these data indicate that upregulation of PDE2A in sympathetic neurons impairs BNP responsiveness, inducing an SHR-like calcium phenotype.

Overexpression of dnPDE2A in cardiac stellate neurons and atria from $S H R$ s rescues the inhibitory action of BNP. Overexpression of catalytically inactive PDE2A was previously shown to increase local levels of cAMP by displacement of endogenous active PDE2A from its intracellular anchor sites $(16,17)$. Therefore, we introduced a dominant-negative PDE2A (dnPDE2A, a catalytically dead mutant of PDE2A) using a viral vector (Ad.CMV-mCherry.dnPDE2A) to assess whether inactive PDE2A can recover the BNP effect in the SHRs. Reduced PDE2A activity in Ad.dnPDE2A-transduced sympathetic ganglia from SHRs was confirmed by measuring cGMP-PDE2A specific activity when compared with those transduced with Ad.mCherry empty virus (Figure 6A). As we expected, $100 \mathrm{nmol} / 1 \mathrm{BNP}$ did not produce any significant 


\section{A}
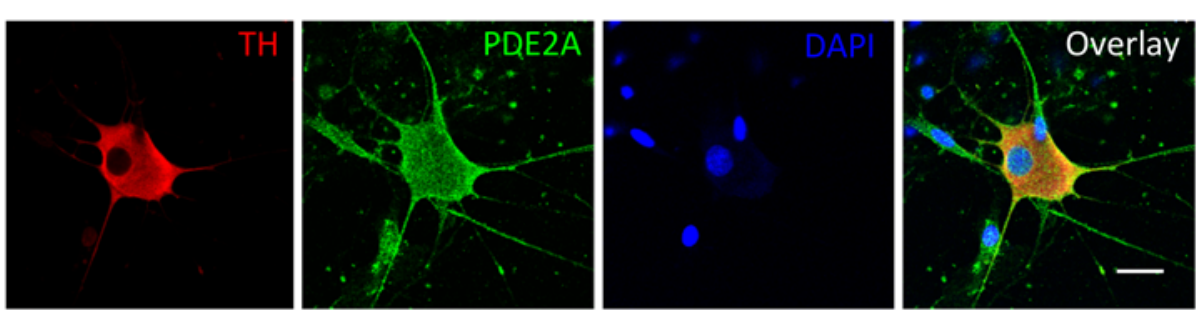

B WKY

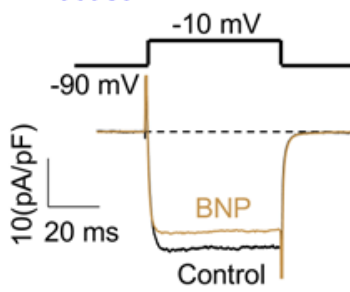

SHR

\section{SHR}
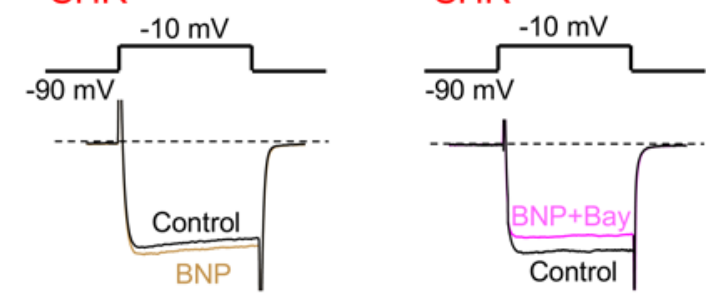

$\mathrm{Vm}(\mathrm{mV})$
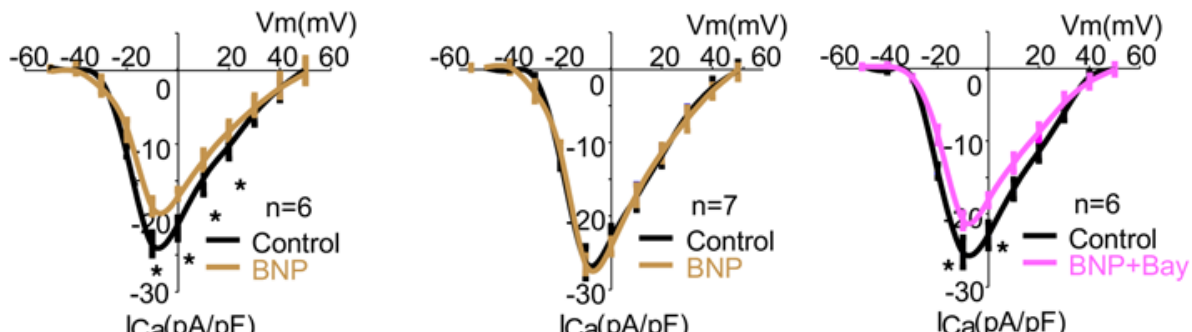

$\mathrm{ICa}(\mathrm{pA} / \mathrm{pF})$

$\mathrm{ICa}(\mathrm{pA} / \mathrm{pF})$

$\mathrm{ICa}(\mathrm{pA} / \mathrm{pF})$

C
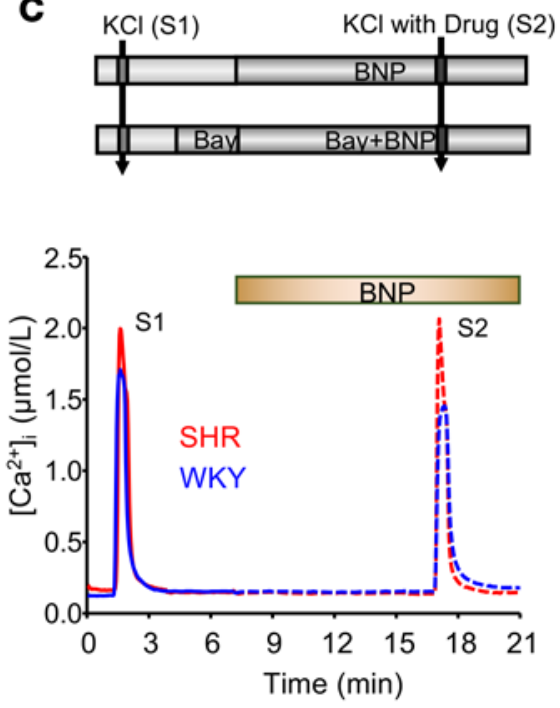

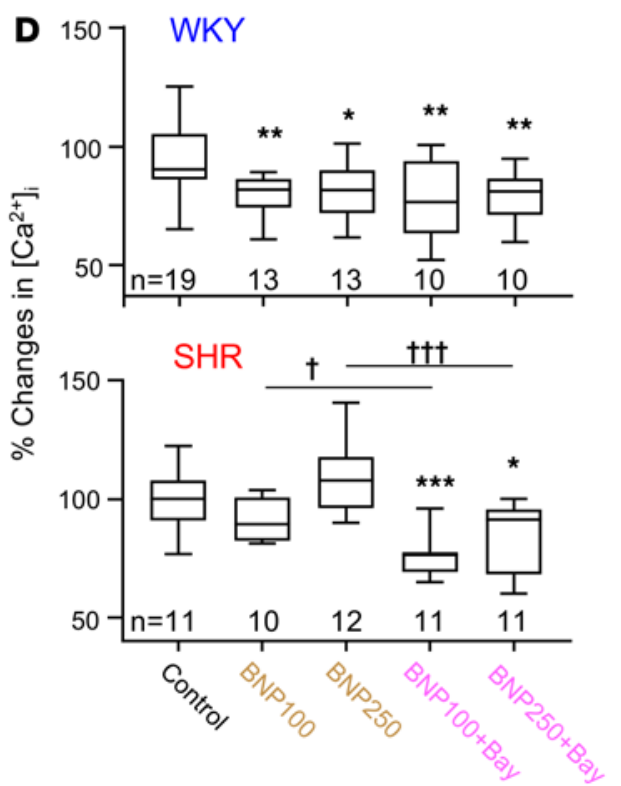

Figure 4. Measurement of calcium current and intracellular free calcium transients in stellate ganglia neurons in the presence of BNP and phosphodiesterase 2A inhibitor. (A) Fluorescence images of a cultured cardiac sympathetic neurons derived from a 4-week-old Wistar Kyoto (WKY) rat stellate ganglion that was stained for the catecholamine neuronal marker tyrosine hydroxylase (TH, red), phosphodiesterase 2A (PDE2A) antibody (green), costained with the nuclear marker DAPI (blue), and overlay. Scale bar: $20 \mu \mathrm{m}$. (B) Representative whole-cell calcium current traces (upper graphs) obtained before and after exposure to $100 \mathrm{nmol} / \mathrm{l}$ brain natriuretic peptide (BNP) (left, middle) or $100 \mathrm{nmol} / \mathrm{l}$ BNP with $1 \mu \mathrm{mol} / \mathrm{l}$ Bay 60-7550 (right) from 4-week-old WKY rats and spontaneously hypertensive rats (SHRs). Currents were evoked by test pulses of $-10 \mathrm{mV}$ from a holding potential of $-90 \mathrm{mV}$. Mean current density-voltage relationships (lower graphs) in the presence and absence of $100 \mathrm{nmol} / \mathrm{l} \mathrm{BNP}$ (left, middle) or $100 \mathrm{nmol} / \mathrm{l} \mathrm{BNP} \mathrm{with} 1 \mu \mathrm{mol} / \mathrm{l}$ Bay $60-7550$ (right) from 4-week-old WKY rats and SHRs. ${ }^{*} P<0.05$ by paired $t$ test. $V m$, membrane voltage in $m V ; I_{\text {ca }}$ indicates calcium current; $p A$, picoampere; $p F$, picofarad. (C) Pharmacological protocols (upper) and raw data trace (lower) recording intracellular calcium transient ([Ca $\left.\left.{ }^{2+}\right]_{i}\right)$ in a single cardiac sympathetic neuron from 4-week-old WKY rats and SHRs. A neuron loaded with fura-2 acetoxymethyl ester (Fura-2/AM, $2 \mu \mathrm{mol} / \mathrm{l}$ ) was stimulated by $50 \mathrm{mmol} / \mathrm{I} \mathrm{KCl}$ for 30 seconds to depolarize the neuron and evoke voltage-gated $\mathrm{Ca}^{2+}$ entry. The size of the first (S1) and second (S2) $\mathrm{KCl}$ stimulation was compared. (D) Group data showing $\mathrm{KCl}$-evoked peak $\left[\mathrm{Ca}^{2+}\right]_{i}$ changes expressed as a ratio (\%) of S2 compared with S1 in response to 100 or $250 \mathrm{nmol} / \mathrm{BNP}$ with or without

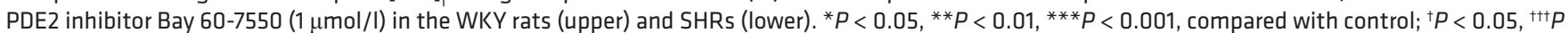
$<0.001$; one-way ANOVA. $n$ indicates the number of neurons. 
A
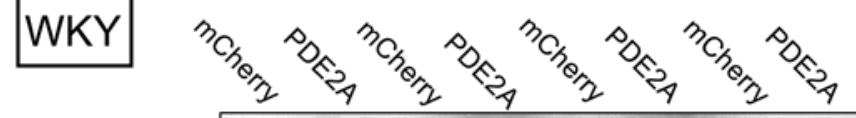

PDE2A.mCherry

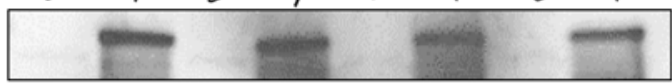

$135 \mathrm{kDa}$

GAPDH

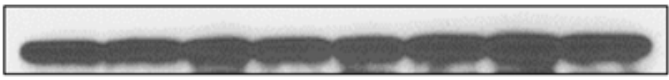

$36 \mathrm{kDa}$

\section{B}
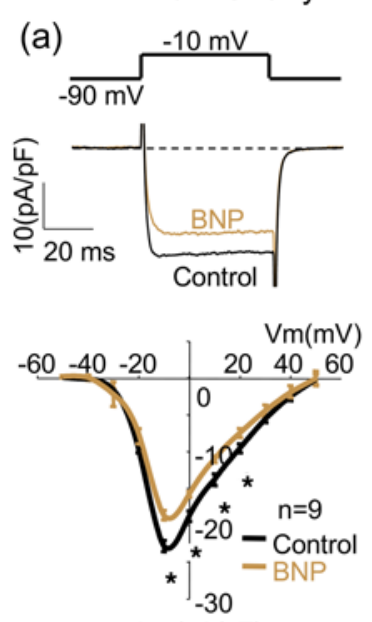

$\mathrm{ICa}(\mathrm{pA} / \mathrm{pF})$

Ad.PDE2A (b)

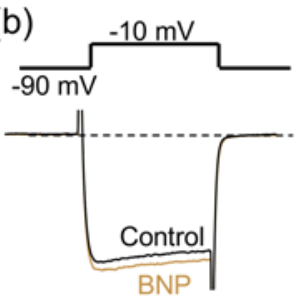

$\mathrm{Vm}(\mathrm{mV})$

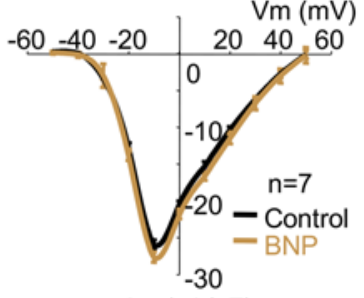

$\mathrm{I} \mathrm{Ca}(\mathrm{pA} / \mathrm{pF})$ (c)

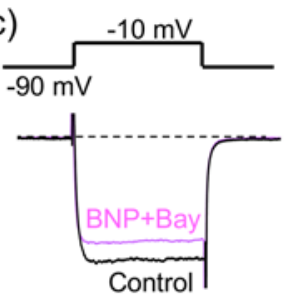

$\mathrm{Vm}(\mathrm{mV})$

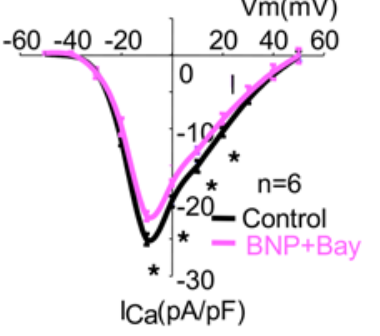

Figure 5. Overexpression of PDE2A in stellate neurons from normotensive rats causes loss of BNP efficacy. (A) Representative Western blot showing PDE2A.mCherry expression (127 kDa) in Wistar Kyoto (WKY) rat stellate ganglia tissue (with anti-PDE2A antibody) 3 days after transduction with Ad.mCherry virus or Ad.mCherryPDE2A. Band optical density was normalized to that of $\beta$-actin $(42 \mathrm{kDa}$ ) as a loading control. $n$ $=4$ in each group, $P<0.05$. (B) Representative calcium current traces (upper graph) and mean current density-voltage relations (lower graph) obtained before and after exposure to 100 $\mathrm{nmol} / \mathrm{l}$ brain natriuretic peptide (BNP) (a, b) or BNP with $1 \mu \mathrm{mol} / \mathrm{l}$ Bay 60-7550 (c) in the transduced with Ad.mCherry virus or Ad.PDE2A from cardiac sympathetic neurons. ${ }^{*} P<0.05$, paired $t$ test. Vm membrane voltage in $\mathrm{mV} ; I_{\mathrm{ca}}$ indicates calcium current; $\mathrm{pA}$, picoampere; $\mathrm{pF}$, picofarad. (C) Percentage change in the peak of intracellular calcium transient $\left(\left[\mathrm{Ca}^{2+}\right]_{i}\right)$ in response of 50 $\mathrm{mmol} / \mathrm{I} \mathrm{KCl}$ for 30 seconds in cardiac sympathetic neurons from WKY rats gene transferred with Ad.mCherry virus or Ad.PDE2A virus in the presence of 100 or $250 \mathrm{nmol} / \mathrm{l} \mathrm{BNP}$ with or without PDE2A inhibitor Bay 60-7550 (1 $\mu \mathrm{mol} / \mathrm{l}) .{ }^{*} P$ $<0.05$, ${ }^{*} P<0.01,{ }^{* *} P<0.001$, compared with control; ${ }^{\dagger} P<0.05$; one-way ANOVA. $n$ indicates the number of neurons.
C

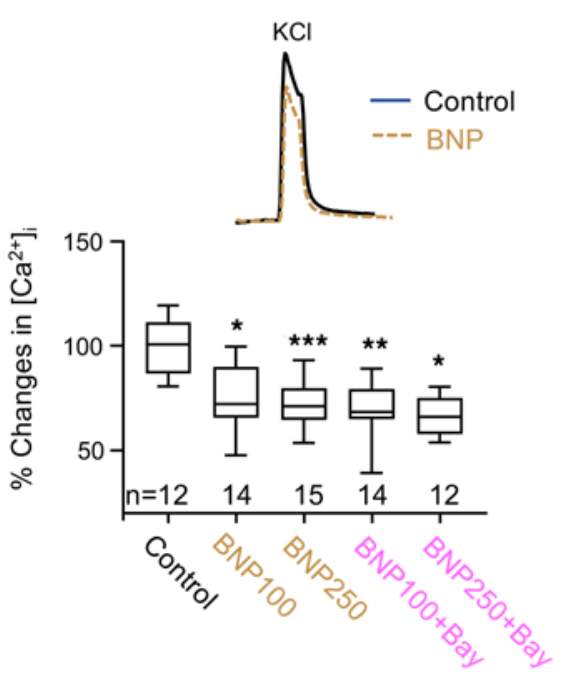

Ad.PDE2A

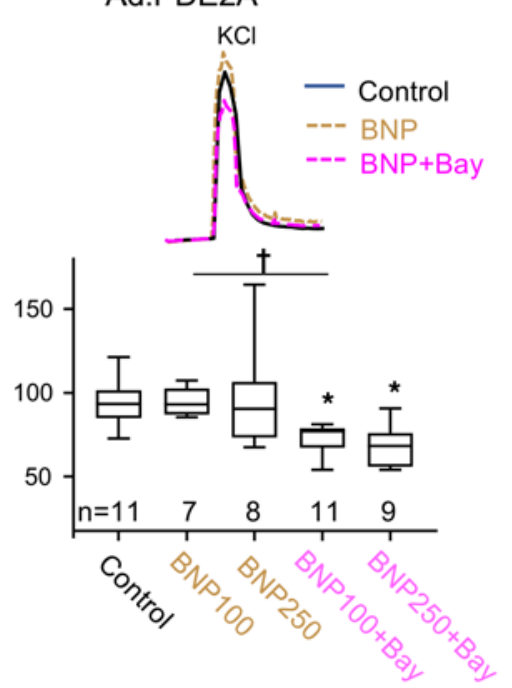

change in the calcium current in the SHRs transduced with the control mCherry viral vector (Figure 6B). However, following Ad.dnPDE2A, $100 \mathrm{nmol} / 1 \mathrm{BNP}$ caused a significant decrease of $I_{\mathrm{CaN}}$ compared with the control $(-18.5 \% \pm 7.9 \%, n=6, P<0.05$; Figure $6 \mathrm{~B})$, indicating that in SHR cells endogenous active PDE2A degrades cGMP generated on BNP stimulation, blocking its effect on $I_{\mathrm{CaN}}$.

We then measured the $\left[\mathrm{Ca}^{2+}\right]_{\mathrm{i}}$ transient in the Ad.dnPDE2A-transduced SG neurons in the SHRs. Similar to the calcium current, BNP (100 and $250 \mathrm{nmol} / \mathrm{l}$ ) did not produce any significant change in $\left[\mathrm{Ca}^{2+}\right]_{\mathrm{i}}$ in SHR neurons transduced with the mCherry vector (Figure 6C). However, in the presence of Bay 60-7550, BNP (100 and $250 \mathrm{nmol} / 1)$ caused a significant decrease of the $\left[\mathrm{Ca}^{2+}\right]_{\mathrm{i}}$ transient compared with the control $(100 \mathrm{nmol} / 1$ : $-17.8 \% \pm 3.8 \%, n=10, P<0.05 ; 250 \mathrm{nmol} / 1:-31.1 \% \pm 3.1 \%, n=9, P<0.001$; Figure 6C). By comparison, treatment with 100 or $250 \mathrm{nmol} / 1 \mathrm{BNP}$ decreased $\left[\mathrm{Ca}^{2+}\right]_{\mathrm{i}}$ transient in dnPDE2A-transduced SHR neurons when compared with control $(-18.1 \% \pm 2.2 \%, n=13, P<0.001 ;-27.6 \% \pm 2.3 \%, n=8, P<0.01$; Figure $6 \mathrm{C})$. 


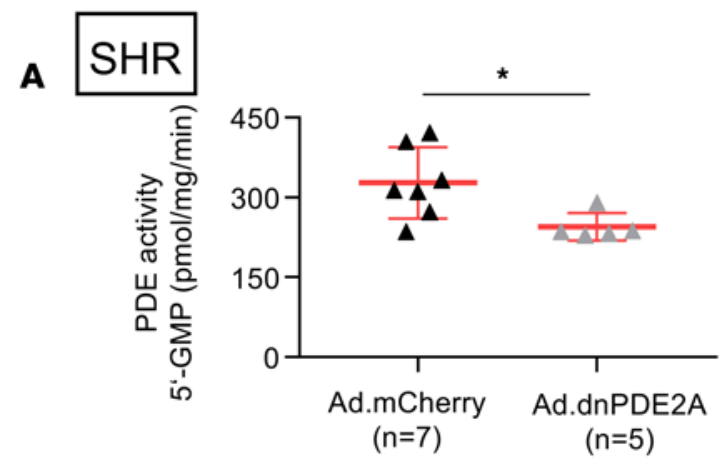

B
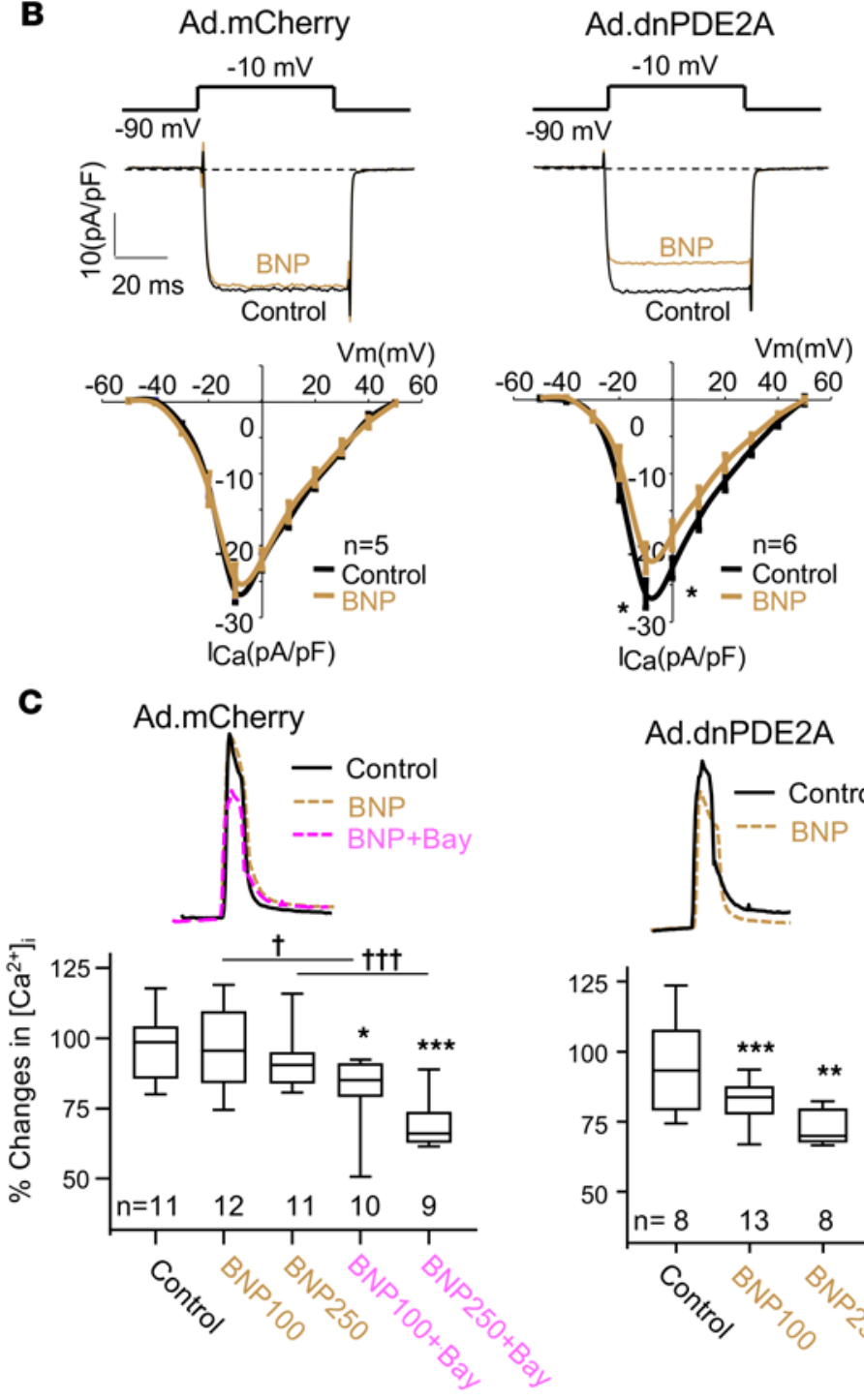

\section{Ad.dnPDE2A}
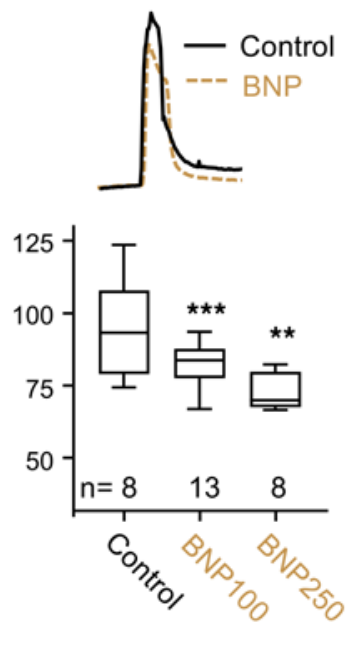

Figure 6. Overexpression of dnPDE2A in stellate neurons from hypertensive rats restores the inhibitory BNP action on calcium signaling. (A) CGMP-PDE specific total activities in stellate ganglia (SC) tissue from 4-weekold spontaneously hypertensive rats (SHRs) transduced with Ad.mCherry or Ad.dnPDE2A. (B) Representative calcium current traces (upper graphs) and mean current density-voltage relations (lower graphs) obtained before and after exposure to $100 \mathrm{nmol} / \mathrm{l}$ BNP in the Ad.mCherry-transduced (left) and Ad.dnPDE2Atransduced (right) SG neurons. ${ }^{*} P$ $<0.05$, paired $t$ test. $V m$ membrane voltage in $\mathrm{mV} ; I_{\text {ca }}$ indicates calcium current; $p A$, picoampere pF, picofarad. (C) Percentage change in the peak of intracellular calcium transient $\left(\left[\mathrm{Ca}^{2+}\right]\right.$ ) in cardiac sympathetic neurons from SHRs gene transferred with Ad.mCherry (left) or Ad.dnPDE2A (right) virus in the presence of 100 or $250 \mathrm{nmol} / \mathrm{l}$ brain natriuretic peptide (BNP) with or without PDE2A inhibitor Bay 60-7550 (1 $\mu \mathrm{mol} / \mathrm{l})$. Both 100 and $250 \mathrm{nmol} / \mathrm{l}$ BNP failed to decrease $\left[\mathrm{Ca}^{2+}\right]_{i}$ with Ad.mCherry virus, unless in the presence of Bay 60-7550 (left). However, 100 and $250 \mathrm{nmol} / \mathrm{I}$ BNP decrease $\left[\mathrm{Ca}^{2+}\right]_{i}$ after transduction with Ad.dnPDE2A (right). ${ }^{*} P$ $<0.05,{ }^{* *} P<0.01,{ }^{* * *} P<0.001$, compared with control; ${ }^{\dagger} P<0.05$ ${ }^{+t+} P<0.001$; one-way ANOVA. $n$ indicates the number of neurons.

For $\left[{ }^{3} \mathrm{H}\right]-\mathrm{NE}$ release, Ad.dnPDE2 transduction did not change the first field stimulation (S1) on the isolated right atrium from the SHRs when compared with the mCherry virus (Figure 7B; Ad.dnPDE2A S1: $+1.22 \% \pm$ $0.12 \%, n=10$, vs. mCherry S1: $+1.35 \% \pm 0.11 \%, n=8, P=0.72$ by 1 -way ANOVA), indicating that the gene transfer of Ad.dnPDE2A did not affect the ability of the neurons to release NE on depolarization. There was no significant change in $\left[{ }^{3} \mathrm{H}\right]-\mathrm{NE}$ release after application of $250 \mathrm{nmol} / 1 \mathrm{BNP}(\mathrm{S} 2)$ in the mCherry virus group when compared with $\mathrm{S} 1$ (S1: $+1.35 \% \pm 0.11 \%$, S2: $+1.4 \% \pm 0.13 \%, n=8, P=0.74$ by 1 -way ANOVA; Figure 7 , A and B). However, in the Ad.dnPDE2A group, BNP $(250 \mathrm{nmol} / 1)$ produced an approximately $50 \%$ reduction in $\left[{ }^{3} \mathrm{H}\right]-\mathrm{NE}$ release $(\mathrm{S} 1:+1.22 \% \pm 0.12 \%, \mathrm{~S} 2:+0.61 \% \pm 0.1 \%, n=10, P<0.01$ by 1 -way ANOVA; Figure 
7, A and B). These data support the hypothesis that reduced PDE2A activity due to inactive PDE2A catalytic domains can rescue the capacity of BNP to reduce $\mathrm{NE}$ release in the stimulated right atrium.

\section{Discussion}

Three potentially novel findings are presented in this study. First, PDE2A is present in human SG where its activity was higher in the left SG from patients with neuro-hormonal hyperactivation compared with control. This molecular phenotype was also seen in SG from hypertensive and prehypertensive rats; in addition, PDE2A mRNA levels were higher in the SHR compared with normal SG. Secondly, the ability of BNP to enhance cGMP production and decrease calcium signaling and neurotransmitter release was impaired in SHR sympathetic neurons. Finally, PDE2A inhibition or catalytically inactive PDE2A can restore the efficacy of BNP to decrease sympathetic neurotransmission in diseased neurons, as depicted in Figure 8.

Impaired response to BNP in the SHR. The physiological actions of the natriuretic peptides in cardiorenal homeostasis and endothelial permeability are well known (18); however, there has been little attention paid to their role in the autonomic nervous system, considering some reports suggest that the BNP analog nesiritide facilitates NE release (13). It is well established that the inhibitory action of BNP on ventricular myocyte calcium signaling is modulated by the NPR-A/cGMP/PKG pathway (19), where PDE2A regulates the hydrolysis of cGMP (5) and decreases the calcium transient (19). We have also reported that BNP produces a direct depressant action on sympathetic nerve function by decreasing NE release and heart rate during sympathetic stimulation in vitro (6). This is the first time to our knowledge that aberrant cGMP signaling has been demonstrated in cardiac sympathetic neurons of SHRs in response to BNP, indicating possible impairment of PDE regulation of cGMP.

In this study, we questioned whether an aspect of the lack of clinical efficacy of BNP in the treatment of essential hypertension $(2,3)$ and heart failure $(9,20)$ may in part be caused by the aberrations in the sympatholytic effects of natriuretic peptides (6) at the level of the postganglionic sympathetic neuron. SHRs have many similarities with human hypertension, including the level of plasma BNP (21) and NE concentrations (22), and chronic progression to cardiac hypertrophy and heart failure (23). They also have a sympatho-vagal phenotype similar to that observed in human hypertension and heart failure $(24,25)$. Results presented here on the SHR model support the hypothesis that BNP not only failed to significantly reduce the calcium transient and the calcium current in depolarized SHR neurons, but it also failed to inhibit NE release. Moreover, higher concentration of BNP actually increased the magnitude of $\mathrm{Ca}^{2+}$ transients in diseased neurons, indicating that BNP coupling to intracellular $\mathrm{Ca}^{2+}$ signaling is impaired. Although the concentrations of BNP used here need to be confirmed as being pathophysiological, natriuretic peptides reach similar concentrations at the postganglionic sympathetic nerve ending in advanced heart failure (13). Nevertheless, we confirm the intimate link between $\left[\mathrm{Ca}^{2+}\right]_{\mathrm{i}}$ and neurotransmitter release. We also show that impaired calcium responses to BNP in SHR neurons abrogates the BNP-mediated reduction in NE release and heart rate (26) that is coupled to overactivity of PDE2A. Overexpressing PDE2A in healthy neurons could mimic the disease phenotype and recapitulate the loss of BNP efficacy in SHR neurons.

The role of PDE2-mediated cGMP hydrolysis in cardiac sympathetic neurons. CAMP and CGMP cross-talk is regulated by the PDE family that is considered important in maintaining cell-signaling processes and cyclic nucleotide balance within specific subcellular microdomains (5). PDEs are involved in different stages of advanced cardiac diseases. PDE1-3 hydrolyze cAMP and cGMP, and both PDE2A and PDE3A have been implicated in the pathogenesis of hypertension $(6,27)$. Some report that the activity of PDE2A towards the hydrolysis of cAMP is relatively low compared with cGMP (28), although it still contributes to the regulation of cardiac L-type calcium channel $\left(I_{\mathrm{CaL}}\right)$ activity, where it inhibits the activation of $I_{\mathrm{CaL}}$ by reducing cAMP concentration after being stimulated by cGMP (29). Our findings support the idea that the activity of neuronal PDE2A is favored towards the hydrolysis of cGMP since PDE2A-induced cAMP activity in the presence of $1 \mu \mathrm{mol} / 1 \mathrm{cGMP}$ resulted in no difference in cAMP levels. Moreover, overexpressed PDE2A reduced cGMP and not cAMP levels in SHR sympathetic neurons. Previously, we have reported that in normal stellate neurons PDE2A inhibition can increase the neuronal calcium current, presumably by slowing cGMP hydrolysis as a consequence of cGMP acting to inhibit PDE3 leading to greater levels of cAMP-PKA activity (14). However, in the present study PDE2A inhibition or IBMX restored BNP-activated cGMP to normal levels (Figure 1B), resulting in a decrease in intracellular calcium handling and neurotransmission.

Although PDE2A is upregulated in cardiomyocytes in human heart failure (4) and angiotensin IIinduced cardiac hypertrophy in rats (28), data are lacking for its role in sympathetic neurons and in car- 
A

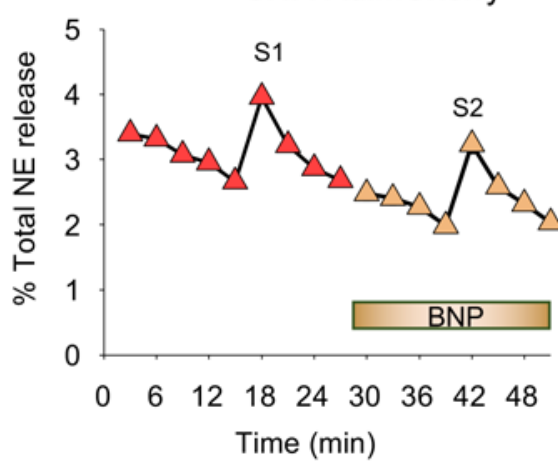

SHR-Ad.dnPDE2A

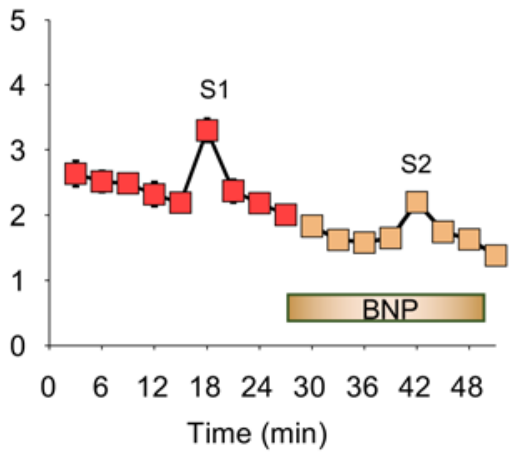

B

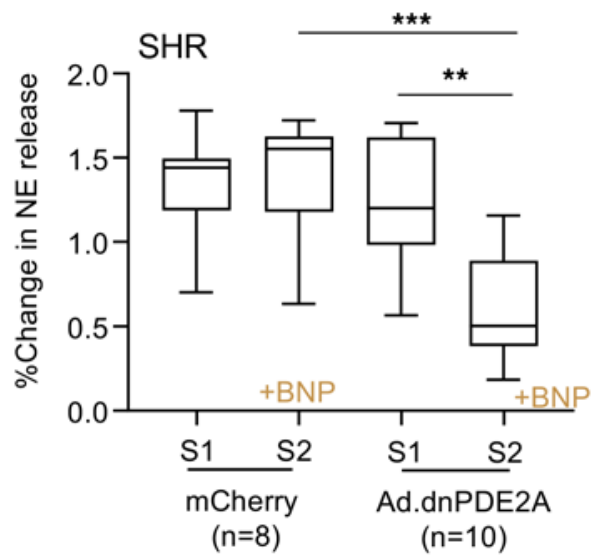

Figure 7. Overexpression of dnPDE2A in atria from hypertensive rat restores the action of BNP on norepinephrine release. (A) Representative raw data trace showing the effect of $250 \mathrm{nmol} / / \mathrm{BNP}$ on $\left[{ }^{3} \mathrm{H}\right]$-norepinephrine $\left(\left[{ }^{3} \mathrm{H}\right]-\mathrm{NE}\right)$ release during 5 - $\mathrm{Hz}$ field stimulation from isolated 4-week-old spontaneously hypertensive rat (SHR) atria gene transferred with Ad.mCherry (left) or Ad.dnPDE2A (right) virus. (B) Group mean data show percentage changes in NE release expressed as a ratio of increase in NE radioactivity after 5 - Hz field stimulation over the total radioactivity. Brain natriuretic peptide (BNP) $(250 \mathrm{nmol} / \mathrm{I})$ significantly reduced $\left[{ }^{3} \mathrm{H}\right]-\mathrm{NE}$ release in SHRs transduced with Ad.dnPDE2A $(n=10)$, but not in the Ad. mCherry group $(n=$ 8). ${ }^{* *} P<0.01,{ }^{* *} P<0.001$ by 1 -way ANOVA.

diac autonomic pathophysiology. Chan et al. have reported a proexocytotic effect of BNP that involves an increase in intraneuronal cAMP resulting from a cGMP-PKG-mediated inhibition of PDE3 in PC12 cells (13). This is in contrast to previous work (6) and the present findings where increased PDE2A is directly linked to enhanced sympathetic transmission in the SHR. Of interest, single-nucleotide polymorphisms, such as rs197163010, are present in PDE2A in the SHR/ola strain (30), and therefore this could provide a genetic basis for the molecular phenotype seen in our SHR neurons. The mechanism underpinning upregulation of PDE2A in disease is not fully understood, but might be related to local neural inflammatory pathways, since TNF- $\alpha$ and IL-6 have been reported to increase PDE2A expression $(31,32)$.

Limitation and clinical perspectives. There is evidence that natriuretic peptide receptor-A (NPR-A) is downregulated in animal models of heart failure $(33,34)$, and that cGMP production by NPR-A is also reduced in the failing heart (35). However, our results have confirmed that NPR-A protein expression is not altered in SHR neurons (data not shown), indicating that NPR-A itself is unlikely to be responsible for the impaired response to BNP in SHR neurons. SG neurons from the SHR may only provide a qualitative cellular surrogate to study the neurobiology of sympathetic impairment in human dysautonomia, even though SG neuronal responses in the SHR and the molecular profile of PDE2A activity closely resembles that seen in human sympathetic pathophysiology. Because of the limited amount of human tissue (disease or donor), we were only able to ascertain a relatively semiquantitative molecular profile. The variance in these data are influenced by the varied pathology of each patient and the extent of their sympathoexcitation. However, we provide the first evidence to our knowledge for the expression of PDE2A in human SG neurons. Whether these levels of neuronal PDE2A negate the sympathetic action of synthetic natriuretic peptides like nesiritide to treat cardiac failure remains to be established. Interestingly, we found that SG neuronal cGMP-PDE specific activity is significantly increased in both sympathetic hyperactive patients and SHR neurons. In particular, this was observed only in the left SG from the patient group in which sympathetic innervation is predominately to the left ventricle where NE spillover is increased in patients with heart failure (36). Moreover, overexpression of PDE2A in healthy neurons mimics the lack of BNP efficacy seen in diseased neurons. Elevated PDE2A activity leads to excessive excitability and increased NE release. The specific inhibitor of PDE2A, Bay 60-7550, and the catalytically inactive PDE2A (dnPDE2A) targeted at cardiac sympathetic neurons rescued the BNP responsiveness in SHR stellate neurons. Therefore, lowering PDE2A activity is consistent with the hypothesis that neuronal PDE2A targeting might be a putative therapeutic strategy to reduce sympathetic activity. Our data are also consistent with the literature, showing increased intraneuronal cGMP upon inhibition of PDE2A (12, 37-40). Thus, activation of PDE2A by particulate guanylyl cyclase-derived (pGC-derived) cGMP in response to NPR-A binding may form a specific regulatory mechanism, limiting the sympatholytic effects of BNP when PDE2A levels are abnormally high. 
A
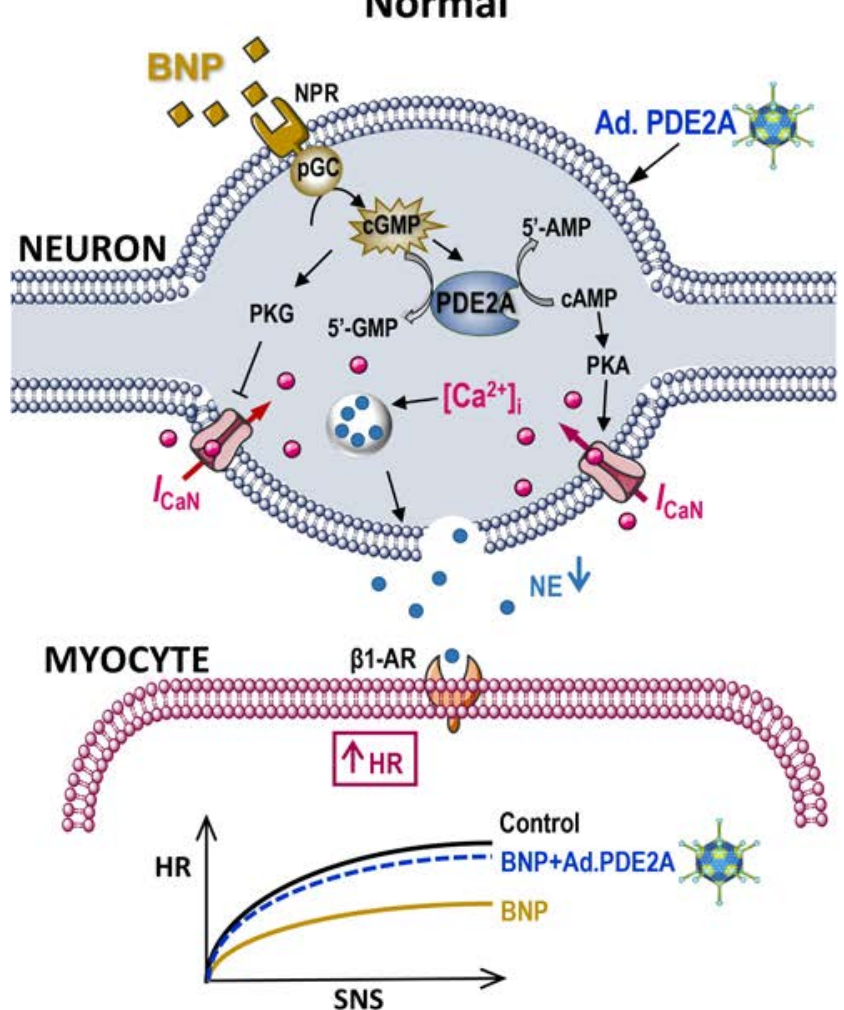

B

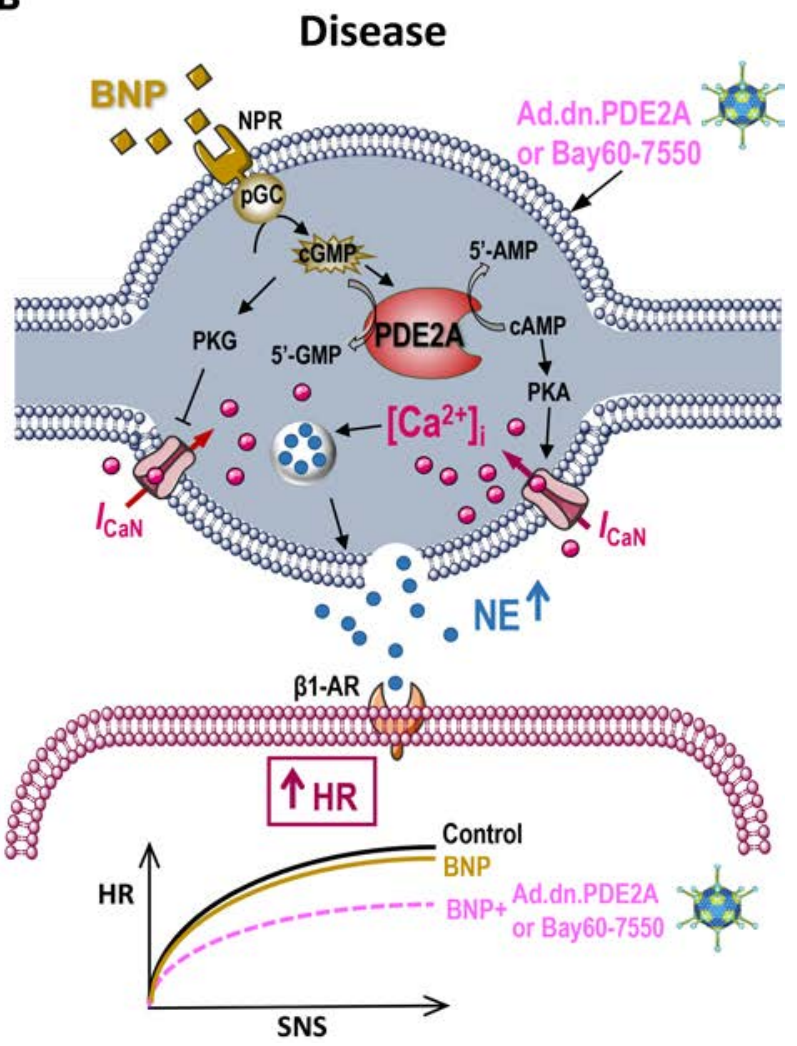

Figure 8. Schematic representation depicting the effect of PDE2A on the regulation of BNP in cardiac neurotransmission in normal and diseased neurons. (A) Brain natriuretic peptide (BNP) can decrease neurotransmission in healthy neurons by activating the particulate guanylyl cyclase-coupled (pGCcoupled) CGMP pathway to decrease intracellular calcium transients and exocytosis resulting in a decrease in the heart rate (HR) response to sympathetic nerve stimulation. Overexpression of PDE2A in healthy neurons mimics the lack of BNP efficacy seen in diseased neurons. (B) In the diseased neuron, PDE2A is increased and increases the hydrolysis of cGMP and decreases the sympatholytic action of BNP that results in an increase in neurotransmission and $\mathrm{HR}$ responses to sympathetic activation. Blockade of overexpressed PDE2A with Bay $60-7550$ or overexpression of catalytically inactive PDE2A reestablished the modulatory action of BNP in the diseased neuron. $\beta 1-A R, \beta 1$-adrenergic receptor; NE, norepinephrine; NPR, natriuretic peptide receptor; SNS, sympathetic nerve stimulation.

\section{Methods}

Human subjects. Table 1 lists the clinical characteristics of the human tissue samples. Bilateral SG were obtained from patients with cardiomyopathy and refractory ventricular arrhythmias undergoing stellate ganglionectomy (6 left and 6 right SG). Control SG were obtained from heart and/or lung donors (8 left and 7 right SG). Patients undergoing elective surgery provided written informed consent. In addition to consent for organ donation, consent to utilize tissues for research was also provided for tissues collected from organ donors. The tissues were immediately frozen in liquid nitrogen and subsequently stored at $-80^{\circ} \mathrm{C}$ for PDE activity measurement, or immediately stored with RNAlater (Ambion, Invitrogen/Thermo Fisher Scientific) for gene expression analysis.

Animals. Four-week-old male prehypertensive SHRs and normotensive WKY rats (sourced from Harlan) that have a well-established cellular sympathetic phenotype were used in this study (41). In addition, some experiments were performed on older rats (38 weeks) that have an established systemic phenotype.

PDE2A activity assay. SG from WKY rats and SHRs or from humans were dissected and rapidly frozen in liquid nitrogen. PDE activity was measured using the PDE Activity Assay Kit (Colorimetric) (Abcam, ab139460) according to the manufacturer's instructions. Briefly, tissues were homogenized in lysis buffer and protease inhibitor cocktail (Sigma-Aldrich), centrifuged at 9,600 $\mathrm{g}\left(4^{\circ} \mathrm{C}, 10\right.$ minutes) in a microfuge. Protein concentration was quantified by Bradford assay; 7-15 $\mu$ g of protein was used per sample. Samples were desalted using 0.5-ml Zeba Spin Desalting Columns (Thermo Fisher Scientific, 89882 ) to remove endogenous free phosphate. Samples were assayed in a reaction mixture (total volume, $50 \mu \mathrm{l} /$ well) containing $200 \mu \mathrm{mol} / 1$ cGMP substrate, 5'-nucleotidase (50 kU/well), and PDE enzyme (20 
$\mathrm{mU} /$ well) for 17 minutes at $30^{\circ} \mathrm{C}$. The reaction was terminated by addition of Green Assay Reagent (100 $\mu \mathrm{l} /$ well). After incubation at room temperature for 25 minutes, the phosphate-dependent color reaction was measured by reading $\mathrm{OD}_{620 \mathrm{~nm}}$ in a microplate-reading spectrophotometer. Individual PDE activities were measured in the absence of the inhibitor as well as in the presence of $1 \mu \mathrm{mol} / 1$ Bay 60-7550, a highly specific PDE2A inhibitor. PDE2A activity is shown as pmol 5'-GMP produced per milligram of protein per minute inhibited by Bay 60-7550.

To judge the contribution of PDE2A to cAMP hydrolysis in SG tissues of 4-week-old WKY rats and SHRs, the same protocol as above was performed except 4-7 $\mu$ g of protein per sample was used, and assayed in $200 \mu \mathrm{mol} / 1 \mathrm{cAMP}$ (instead of cGMP) substrate plus $1 \mu \mathrm{M}$ cGMP as an allosteric activator, and incubated for 10 minutes at $30^{\circ} \mathrm{C}$.

RNA extraction and $q R T-P C R$. Total RNA from SG from WKY rats and SHRs or human tissue was extracted using a RNeasy Protect Mini Kit (Qiagen) according to the manufacturer's instructions. For reverse transcription, first-strand cDNA was synthesized from $1 \mu \mathrm{g}$ of total RNA with the iScript cDNA Synthesis Kit (Bio-Rad) according to the manufacturer's protocol. qRT-PCR was conducted in a total of $20 \mu 1$ containing $10 \mu \mathrm{l}$ of Taqman Universal PCR Master mix (Applied Biosystems), $4 \mu 1$ of cDNA (10 ng/ $\mu 1), 1 \mu 1$ of $20 \times$ specific primers for Taqman Gene Expression Assays (Rn01648917_m1 for PDE2A of rat, Hs00159935_m1 for PDE2A of human, Rn00667869_m1 for $\beta$-actin of rat, Hs01060665_g1 for $\beta$-actin of human; Thermo Fisher Scientific), and $5 \mu \mathrm{l}$ of DNase-free water. qRT-PCR was performed in a 96-well clear optical reaction plate 7000 apparatus (Applied Biosystems), and the thermal cycling conditions were 2 minutes at $50^{\circ} \mathrm{C}, 10 \mathrm{~min}$ utes at $95^{\circ} \mathrm{C}$, followed by 40 cycles of 15 seconds at $95^{\circ} \mathrm{C}$ and 1 minutes at $60^{\circ} \mathrm{C}$. All samples and standards were run as triplicates. Results were analyzed with the ABI Prism 7000 Sequence Detection System software (Applied Biosystems). Gene expression was normalized to $\beta$-actin that was used as an internal control.

$\left.{ }^{\beta} \mathrm{H}\right]-\mathrm{NE}$ release experiments on the isolated right atrium. The spontaneously beating rat atrium was isolated and transferred to a preheated $\left(37^{\circ} \mathrm{C} \pm 0.2^{\circ} \mathrm{C}\right.$ ), continuously oxygenated (carbogen: $95 \%$ oxygen, $5 \% \mathrm{CO}_{2}$ ), water-jacketed organ bath containing $3 \mathrm{ml}$ Tyrode solution where the atrium was pinned flat on a silver stimulating electrode. The method for determining the local release of ${ }^{3} \mathrm{H}-\mathrm{NE}$ to $5-\mathrm{Hz}$ field stimulation (15 V, $1 \mathrm{~ms}$ pulse width, for 1 minute) was identical to that which we have previously described (42).

Primary cultures of dissociated sympathetic neurons. Sympathetic neurons were isolated from SHRs and WKY rats using a previously described method (41). Briefly, the SG were dissected from the rats and neurons enzymatically dissociated with collagenase and trypsin at $37^{\circ} \mathrm{C}$. After a sequential mechanical trituration, the cell suspension containing SG neurons was plated onto poly-D-lysine/laminin-coated coverslips and incubated at $37^{\circ} \mathrm{C}$ in a humidified atmosphere of $95 \%$ air $/ 5 \% \mathrm{CO}_{2}$. Experiments were performed 2 or 3 days after plating.

Adenovirus vector transduction. An adenoviral vector expressing PDE2A or catalytically inactive PDE2A (dnPDE2A) tagged with red fluorescent protein mCherry (Ad.CMV-mCherry/PDE2A or Ad.CMVmCherry/dnPDE2A) (43) was transduced into cultured cardiac sympathetic neurons (for calcium current and transient measurements) or isolated SG tissue (for Western blot). An adenoviral vector expressing only mCherry (Ad.CMV-mCherry) was used as a control for comparing the effect of viral transduction. Adenoviral vector $\left(5 \times 10^{7} \mathrm{PFU}\right)$ was used to infect neurons or ganglia in a 4 -well plate $\left(1.9 \mathrm{~cm}^{2} /\right.$ well, Nunc) The virus-containing medium was left in the well overnight before changing to fresh medium. Experiments were performed 3 days following gene transfer, except that the patch-clamp recordings were performed at 12-22 hours to minimize problems with space clamp (14).

For the evoked NE release experiment, targeted percutaneous gene transfer to the right atrium of rats was performed under isoflurane anesthesia (4\% for induction and $2 \%-3 \%$ for maintenance in $100 \% \mathrm{O}_{2}$ ), using a technique similar to that described previously for the guinea pig (44). WKY rats and SHRs received an injection of $5 \times 10^{8} \mathrm{PFU} / \mathrm{ml}$ of Ad.dnPDE2A or Ad.PDE2A in $300 \mu 1$ of sterile phosphate-buffered saline. Physiological phenotyping was performed 4 days after the injection.

Real-time analysis of cGMP dynamics. FRET imaging was used to measure the intracellular cGMP. An adenoviral vector expressing the reporter cGi500 (provided by Michael Russwurm, Department of Pharmacology and Toxicology, Ruhr University Bochum, Bochum, Germany) (45) was used as the cGMP biosensor under the control of the human CMV promoter. A Nikon microscope was connected to an OptoLED fluorescence imaging system (Cairn Research Ltd.) equipped with a 40× oil-immersion objective, a CoolSNAP HQ2 digital CCD camera (Photometrics), and a beam-splitter (DV2, Photometrics) including the specific set of emission filters for donor and acceptor fluorophore acquisition (dichroic mirror 505DCXR, donor emission of $480 \mathrm{~nm}$, and acceptor emission of $535 \mathrm{~nm}$; Chroma Technology Corp). 
Images were obtained every 15 seconds. FRET values were measured as changes in the ratio between 480/535-nm fluorescent emission intensities after background subtraction upon excitation at $430 \mathrm{~nm}$. The 480/535-nm emission intensity ratio was plotted against time, and the mean FRET response was expressed as the percentage of $\Delta R / R_{0}$, in which $\Delta R=R-R_{0} . R_{0}$ is the mean of the FRET ratio values calculated from the 4 images acquired before the addition of the first drug, and $R$ is the ratio at time $=t$ seconds.

Patch-clamp recordings. Calcium currents were recorded using conventional whole-cell techniques (14). Pipette resistance varied from 1.5 to $2 \mathrm{M} \Omega$ when filled with the internal solution containing (in mmol/1) 140 $\mathrm{CsCl}, 10 \mathrm{HEPES}, 0.1 \mathrm{CaCl}_{2}, 4 \mathrm{MgATP}, 1 \mathrm{MgCl}_{2}$, and 1 EGTA, adjusted to $\mathrm{pH} 7.4$ with $\mathrm{CsOH}$. The isolated neurons were superfused in a $36^{\circ} \mathrm{C} \pm 0.5^{\circ} \mathrm{C}$ bath with external solution containing (in mmol/1) $145 \mathrm{TEACl}, 10$ HEPES, $4.5 \mathrm{KCl}, 1 \mathrm{MgCl}_{2}, 11$ glucose, $1 \mathrm{NaHCO}_{3}, 2 \mathrm{BaCl}_{2}$, and 0.001 tetrodotoxin, adjusted to $\mathrm{pH} 7.4$ with Sigma base 7-9. Barium was chosen to isolate calcium currents and avoid Ca-dependent current inactivation (46); $I_{\mathrm{Ba}}$ refers to $I_{\mathrm{Ca}}$, unless otherwise specified. The bath was grounded by an $\mathrm{Ag} / \mathrm{AgCl}$ electrode connected via a $3 \mathrm{~mol} / 1 \mathrm{KCl} /$ agar salt bridge. Calcium currents were acquired using Clampex software via an Axopatch 200B amplifier. Series resistance was compensated between $75 \%$ and $90 \%$. Current-voltage (I-V) relationships were elicited from a holding potential of $-90 \mathrm{mV}$ using 50 -ms steps (5 seconds between steps) to test potentials over the range of -50 to $+50 \mathrm{mV}$ in $10-\mathrm{mV}$ increments. Current amplitude data of each cell were normalized to its capacitance and expressed as current density $(\mathrm{pA} / \mathrm{pF})$.

Measurement of $\left[\mathrm{Ca}^{2+}\right]_{i}$. Intracellular free calcium concentration $\left(\left[\mathrm{Ca}^{2+}\right]_{\mathrm{i}}\right)$ was determined in single neurons using Fura-2/AM ( $2 \mu \mathrm{mol} / 1)$. Loaded neurons were imaged with a QICLICK digital CCD camera (Photometrics) connected to the OptoLED fluorescence imaging system housed on an inverted Nikon microscope equipped with a $40 \times$, oil-immersion objective. The coverslip containing the neurons was placed into a temperature-controlled $\left(36^{\circ} \mathrm{C} \pm 0.5^{\circ} \mathrm{C}\right)$, gravity-fed perfusion chamber (volume: $100 \mu 1$ ), perfused with Tyrode solution at a flow rate of $2 \mathrm{ml} / \mathrm{min}$. The evoked $\left[\mathrm{Ca}^{2+}\right]_{\mathrm{i}}$ transient was evaluated by 30 -second exposure to $50 \mathrm{mmol} / 1 \mathrm{KCl}$ (with equimolar reduction in $\mathrm{NaCl}$ ) in the Tyrode solution. Fura-2/AM was excited alternately at $355 \mathrm{~nm}$ and $380 \mathrm{~nm}$ and the emission detected at $510 \mathrm{~nm}$. Fluorescence excitation ratios were transformed into $\left[\mathrm{Ca}^{2+}\right]_{\mathrm{i}}$ concentrations using the equation derived by Grynkiewicz (47): $\left[\mathrm{Ca}^{2+}\right]_{\mathrm{i}}$ $=K_{d} \times\left(\mathrm{S}_{\mathrm{f} 2} / \mathrm{S}_{\mathrm{b} 2}\right) \times\left(R-R_{\min }\right) /\left(R_{\max }-R\right)$.

Western blot. Cultured tissues were homogenized in ice-cold lysis buffer with proteinase inhibitors and quantified by Bradford Protein Assay Kit. A total of $30 \mu \mathrm{g}$ protein was separated in denaturing acrylamide gels (4\%-12\% Criterion XT Bis-Tris Precast Gels, Bio-Rad). After transfer to PVDF membranes (Sequi-Blot PVDF Membrane Roll, Bio-Rad), the membranes were blocked with $0.5 \%$ skimmed milk for 1 hour. Primary antibody against PDE2A (Proteintech, 55306-1-AP; 1:450) was incubated overnight at $4^{\circ} \mathrm{C}$. After incubation with secondary antibody (goat anti-rabbit IgG (H+L), HRP, Thermo Fisher Scientific, 31460; 1:4,000) for 1 hour, proteins were visualized by enhanced chemiluminescence and quantified with UN-SCAN-IT gel Digitizing 6.1 software (Silk Scientific, Inc). The results were normalized to GAPDH that served as a loading control (Proteintech, 10494-1-AP; 1:5,000). Brain lysate was used as a positive control throughout the experiments.

Immunofluorescence. Cultured primary neurons were fixed in acetone/methanol for 10 minutes, followed by antigen blocking in 1\% BSA and with primary antibody against TH (mouse mAb, Sigma-Aldrich, AB152; 1:1,000) or anti- PDE2A (rabbit pAb, Thermo Fisher Scientific, PA1-31128; 1:500) in 1\% BSA overnight at $4^{\circ} \mathrm{C}$. Signals were visualized with Alexa Fluor 594 anti-mouse IgG (H+L) (Invitrogen, A21203; 1:1,000) and Alexa Fluor 488 anti-rabbit IgG $(\mathrm{H}+\mathrm{L})$ (Invitrogen, A21206; 1:1,000), respectively. Nuclear staining was performed with 4',6-diamidino-2-phenylindole (DAPI, Sigma-Aldrich, D9542).

Statistics. Data are expressed as means \pm SEM. All statistical calculations were performed using the SigmaPlot 12.5 software package (Systat Software Inc.). For comparison of 2 groups, an unpaired 2-tailed $t$ test was performed, or a Mann-Whitney rank-sum test if the data were not normally distributed. To compare more than 2 groups, 1-way ANOVA was performed and the Holm-Sidak method was used as a post hoc test. Paired $t$ test was performed when comparing S1 and S2. For all experiments, statistical significance was accepted at $P<0.05$.

Study approval. The study was approved by the UCLA IRB (approval number 12-000701) and a materials transfer agreement into the University of Oxford Bio-Bank (MAT2015-705). Written informed consent was provided by the patient or appropriate designee. For organ donors, consent for research was provided by the donor or appropriate signatory. Animal experiments conformed to the NIH Guide for Care and Use of Laboratory Animals (publication no. 85-23, revised 1996) and Animals (Scientific Procedures) Act 1986 (United Kingdom). Procedures were performed under British Home Office license requirements (PPL 30/3131). 


\section{Author contributions}

KL performed Western blots, qRT-PCR, $\left[{ }^{3} \mathrm{H}\right]-\mathrm{NE}$ release, calcium transient measurements, analyzed data, and drafted the manuscript. DL participated in design of the study, supervision, performed PDE activity assay, analyzed data, and cowrote the manuscript. GH performed patch-clamp recordings and analyzed data. DM, ON, LW, and DI performed FRET and measured the calcium transient. CJL performed the in vivo injections. $\mathrm{MB}$ and $\mathrm{MZ}$ provided the reporter and contributed towards the FRET experimental design. HT, OAA, JLA, and KS provided human tissue and edited the manuscript. DJP oversaw experiments, design, supervision, resources, and edited the manuscript. All authors reviewed the manuscript.

\section{Acknowledgments}

This project was supported by grants from the British Heart Foundation (BHF, PG/14/41/30877 to D.J. Paterson and D. Li; PG/10/75/28537 and RG/12/3/29423 to M. Zaccolo), the BHF Centre of Research Excellence, Oxford (RE/13/1/30181 to D.J. Paterson and M. Zaccolo) and US NIH SPARC program (1OT2OD023848). The authors wish to acknowledge the support of One Legacy in obtaining donor tissue samples. We also thank Andreas Koschinski for technical assistance.

Address correspondence to: David J. Paterson or Dan Li, Burdon Sanderson Cardiac Science Centre, Department of Physiology, Anatomy and Genetics, Sherrington Building, Parks Road, Oxford, OX1 3PT, United Kingdom. Phone: 44.0.1865272471; Email: david.paterson@dpag.ox.ac.uk (D.J. Paterson). Phone: 44.0.1865272547; Email: dan.li@dpag.ox.ac.uk (D. Li). Or to: Kalyanam Shivkumar, UCLA Cardiac Arrhythmia Center, David Geffen School of Medicine, UCLA Health System, Los Angeles, California 90025, USA. Phone: 310.206.6433; Email: KShivkumar@mednet.ucla.edu.

CJL's present address is the Michael Smith Laboratories, University of British Columbia, Vancouver, Canada.

1. Tsutamoto T, et al. Attenuation of compensation of endogenous cardiac natriuretic peptide system in chronic heart failure: prognostic role of plasma brain natriuretic peptide concentration in patients with chronic symptomatic left ventricular dysfunction. Circulation. 1997;96(2):509-516.

2. Richards AM, Crozier IG, Holmes SJ, Espiner EA, Yandle TG, Frampton C. Brain natriuretic peptide: natriuretic and endocrine effects in essential hypertension. J Hypertens. 1993;11(2):163-170.

3. La Villa G, et al. Cardiovascular effects of brain natriuretic peptide in essential hypertension. Hypertension. 1995;25(5):1053-1057.

4. Mehel H, et al. Phosphodiesterase-2 is up-regulated in human failing hearts and blunts $\beta$-adrenergic responses in cardiomyocytes. J Am Coll Cardiol. 2013;62(17):1596-1606.

5. Zaccolo M, Movsesian MA. cAMP and cGMP signaling cross-talk: role of phosphodiesterases and implications for cardiac pathophysiology. Circ Res. 2007;100(11):1569-1578.

6. Li D, et al. Efficacy of B-type natriuretic peptide is coupled to phosphodiesterase 2A in cardiac sympathetic neurons. Hypertension. 2015;66(1):190-198.

7. McFarlane SI, Winer N, Sowers JR. Role of the natriuretic peptide system in cardiorenal protection. Arch Intern Med. 2003;163(22):2696-2704.

8. Herring N, Paterson DJ. Neuromodulators of peripheral cardiac sympatho-vagal balance. Exp Physiol. 2009;94(1):46-53.

9. Yancy CW, et al. The Second Follow-up Serial Infusions of Nesiritide (FUSION II) trial for advanced heart failure: study rationale and design. Am Heart J. 2007;153(4):478-484.

10. O'Connor CM, et al. Effect of nesiritide in patients with acute decompensated heart failure. N Engl J Med. 2011;365(1):32-43.

11. Sackner-Bernstein JD, Kowalski M, Fox M, Aaronson K. Short-term risk of death after treatment with nesiritide for decompensated heart failure: a pooled analysis of randomized controlled trials. JAMA. 2005;293(15):1900-1905.

12. Boess FG, et al. Inhibition of phosphodiesterase 2 increases neuronal cGMP, synaptic plasticity and memory performance. Neuropharmacology. 2004;47(7):1081-1092.

13. Chan NY, Seyedi N, Takano K, Levi R. An unsuspected property of natriuretic peptides: promotion of calcium-dependent catecholamine release via protein kinase G-mediated phosphodiesterase type 3 inhibition. Circulation. 2012;125(2):298-307.

14. Larsen HE, Bardsley EN, Lefkimmiatis K, Paterson DJ. Dysregulation of neuronal $\mathrm{Ca}^{2+}$ channel linked to heightened sympathetic phenotype in prohypertensive states. J Neurosci. 2016;36(33):8562-8573.

15. Ajijola OA, et al. Inflammation, oxidative stress, and glial cell activation characterize stellate ganglia from humans with electrical storm. JCI Insight. 2017;2(18):94715.

16. Stangherlin A, et al. cGMP signals modulate cAMP levels in a compartment-specific manner to regulate catecholamine-dependent signaling in cardiac myocytes. Circ Res. 2011;108(8):929-939.

17. Monterisi S, et al. PDE2A2 regulates mitochondria morphology and apoptotic cell death via local modulation of cAMP/PKA signalling. Elife. 2017;6:e21374.

18. Levin ER, Gardner DG, Samson WK. Natriuretic peptides. N Engl J Med. 1998;339(5):321-328.

19. Sodi R, Dubuis E, Shenkin A, Hart G. B-type natriuretic peptide (BNP) attenuates the L-type calcium current and regulates ven- 
tricular myocyte function. Regul Pept. 2008;151(1-3):95-105.

20. Yancy CW, et al. Safety and efficacy of outpatient nesiritide in patients with advanced heart failure: results of the Second Follow-Up Serial Infusions of Nesiritide (FUSION II) trial. Circ Heart Fail. 2008;1(1):9-16.

21. Yokota N, et al. Alterations in circulating and cardiac tissue concentrations of brain natriuretic peptide in spontaneously hypertensive rats. Cardiovasc Res. 1993;27(7):1312-1315.

22. Zugck C, Lossnitzer D, Backs J, Kristen A, Kinscherf R, Haass M. Increased cardiac norepinephrine release in spontaneously hypertensive rats: role of presynaptic alpha-2A adrenoceptors. J Hypertens. 2003;21(7):1363-1369.

23. Sen S, Tarazi RC, Khairallah PA, Bumpus FM. Cardiac hypertrophy in spontaneously hypertensive rats. Circ Res. 1974;35(5):775-781.

24. Nolan J, et al. Prospective study of heart rate variability and mortality in chronic heart failure: results of the United Kingdom heart failure evaluation and assessment of risk trial (UK-heart). Circulation. 1998;98(15):1510-1516.

25. La Rovere MT, Bigger JT, Marcus FI, Mortara A, Schwartz PJ. Baroreflex sensitivity and heart-rate variability in prediction of total cardiac mortality after myocardial infarction. ATRAMI (Autonomic Tone and Reflexes After Myocardial Infarction) Investigators. Lancet. 1998;351(9101):478-484.

26. Shanks J, Mane S, Ryan R, Paterson DJ. Ganglion-specific impairment of the norepinephrine transporter in the hypertensive rat. Hypertension. 2013;61(1):187-193.

27. Boda H, et al. A PDE3A mutation in familial hypertension and brachydactyly syndrome. J Hum Genet. 2016;61(8):701-703.

28. Mokni W, et al. Concerted regulation of cGMP and cAMP phosphodiesterases in early cardiac hypertrophy induced by angiotensin II. PLoS One. 2010;5(12):e14227.

29. Fischmeister R, Castro L, Abi-Gerges A, Rochais F, Vandecasteele G. Species- and tissue-dependent effects of NO and cyclic GMP on cardiac ion channels. Comp Biochem Physiol, Part A Mol Integr Physiol. 2005;142(2):136-143.

30. Yates A, et al. Ensembl 2016. Nucleic Acids Res. 2016;44(D1):D710-D716.

31. Chen W, et al. Endothelial actions of ANP enhance myocardial inflammatory infiltration in the early phase after acute infarction. Circ Res. 2016;119(2):237-248.

32. Wang JN, Zhao XJ, Liu ZH, Zhao XL, Sun T, Fu ZJ. Selective phosphodiesterase-2A inhibitor alleviates radicular inflammation and mechanical allodynia in non-compressive lumbar disc herniation rats. Eur Spine J. 2017;26(7):1961-1968.

33. Cabiati M, Campan M, Caselli C, Prescimone T, Giannessi D, Del Ry S. Sequencing and cardiac expression of natriuretic peptide receptors A and C in normal and heart failure pigs. Regul Pept. 2010;162(1-3):12-17.

34. Kuhn M. Structure, regulation, and function of mammalian membrane guanylyl cyclase receptors, with a focus on guanylyl cyclase-A. Circ Res. 2003;93(8):700-709.

35. Dickey DM, Flora DR, Bryan PM, Xu X, Chen Y, Potter LR. Differential regulation of membrane guanylyl cyclases in congestive heart failure: natriuretic peptide receptor (NPR)-B, Not NPR-A, is the predominant natriuretic peptide receptor in the failing heart. Endocrinology. 2007;148(7):3518-3522.

36. Meredith IT, Eisenhofer G, Lambert GW, Dewar EM, Jennings GL, Esler MD. Cardiac sympathetic nervous activity in congestive heart failure. Evidence for increased neuronal norepinephrine release and preserved neuronal uptake. Circulation. 1993;88(1):136-145.

37. Machowska A, Juszczak K, Novak P, Thor P. The natriuretic peptide neurohormonal system modulation by vasopeptidase inhibitors--the novel therapeutical approach of hypertension treatment. Folia Med Cracov. 2009;50(3-4):35-42.

38. Masood A, Nadeem A, Mustafa SJ, O'Donnell JM. Reversal of oxidative stress-induced anxiety by inhibition of phosphodiesterase-2 in mice. J Pharmacol Exp Ther. 2008;326(2):369-379.

39. Suvarna NU, O'Donnell JM. Hydrolysis of N-methyl-D-aspartate receptor-stimulated cAMP and cGMP by PDE4 and PDE2 phosphodiesterases in primary neuronal cultures of rat cerebral cortex and hippocampus. J Pharmacol Exp Ther. 2002;302(1):249-256.

40. Xu Y, et al. Phosphodiesterase-2 inhibitor reverses corticosterone-induced neurotoxicity and related behavioural changes via cGMP/PKG dependent pathway. Int J Neuropsychopharmacol. 2013;16(4):835-847.

41. Li D, et al. Targeted neuronal nitric oxide synthase transgene delivery into stellate neurons reverses impaired intracellular calcium transients in prehypertensive rats. Hypertension. 2013;61(1):202-207.

42. Li D, Wang L, Lee CW, Dawson TA, Paterson DJ. Noradrenergic cell specific gene transfer with neuronal nitric oxide synthase reduces cardiac sympathetic neurotransmission in hypertensive rats. Hypertension. 2007;50(1):69-74.

43. Zoccarato A, et al. Cardiac hypertrophy is inhibited by a local pool of cAMP regulated by phosphodiesterase 2. Circ Res. 2015;117(8):707-719.

44. Mohan RM, et al. Neuronal nitric oxide synthase gene transfer promotes cardiac vagal gain of function. Circ Res. 2002;91(12):1089-1091.

45. Russwurm M, Mullershausen F, Friebe A, Jäger R, Russwurm C, Koesling D. Design of fluorescence resonance energy transfer (FRET)-based cGMP indicators: a systematic approach. Biochem J. 2007;407(1):69-77.

46. Imredy JP, Yue DT. Mechanism of Ca(2+)-sensitive inactivation of L-type Ca ${ }^{2+}$ channels. Neuron. 1994;12(6):1301-1318.

47. Grynkiewicz G, Poenie M, Tsien RY. A new generation of $\mathrm{Ca}^{2+}$ indicators with greatly improved fluorescence properties. $J$ Biol Chem. 1985;260(6):3440-3450 